\title{
A Comparative Analysis of Ethnomedicinal Practices for Treating Gastrointestinal Disorders Used by Communities Living in Three National Parks (Korea)
}

\author{
Hyun Kim, ${ }^{1}$ Mi-Jang Song, ${ }^{2}$ Heldenbrand Brian, ${ }^{3}$ and Kyoungho Choi ${ }^{4}$ \\ ${ }^{1}$ School of Alternative Medicine and Health Science, Jeonju University, 303 Cheonjam-ro, Wansan-gu, \\ Jeonju 560-759, Republic of Korea \\ ${ }^{2}$ Department of Integrated Bioresource Science, Graduate School of Jeonju University, 303 Cheonjam-ro, Wansan-gu, \\ Jeonju 560-759, Republic of Korea \\ ${ }^{3}$ School of Liberal Arts, Jeonju University, 303 Cheonjam-ro, Wansan-gu, Jeonju 560-759, Republic of Korea \\ ${ }^{4}$ Department of Basic Medical Science, Jeonju University, 303 Cheonjam-ro, Wansan-gu, Jeonju 560-759, Republic of Korea
}

Correspondence should be addressed to Hyun Kim; hyunk@jj.ac.kr

Received 3 March 2014; Accepted 16 May 2014; Published 17 August 2014

Academic Editor: Rainer W. Bussmann

Copyright (C) 2014 Hyun Kim et al. This is an open access article distributed under the Creative Commons Attribution License, which permits unrestricted use, distribution, and reproduction in any medium, provided the original work is properly cited.

\begin{abstract}
The purpose of this study is to comparatively analyze the ethnomedicinal practices on gastrointestinal disorders within communities in Jirisan National Park, Gayasan National Park, and Hallasan National Park of Korea. Data was collected through participant observations and indepth interviews with semistructured questionnaires. Methods for comparative analysis were accomplished using the informant consensus factor, fidelity level, and internetwork analysis. A total of 490 ethnomedicinal practices recorded from the communities were classified into 110 families, 176 genera, and 220 species that included plants, animals, fungi, and alga. The informant consensus factor values in the disorder categories were enteritis, and gastralgia (1.0), followed by indigestion (0.94), constipation (0.93), and abdominal pain and gastroenteric trouble (0.92). In terms of fidelity levels, 71 plant species showed fidelity levels of $100 \%$. The internetwork analysis between disorders and all medicinal species are grouped in the center by the four categories of indigestion, diarrhea, abdominal pain, and gastroenteric trouble, respectively. Regarding the research method of this study, the comparative analysis methods will contribute to the availability of orally transmitted ethnomedicinal knowledge. Among the methods of analysis, the use of internetwork analysis as a tool for analysis in this study provides imperative internetwork maps between gastrointestinal disorders and medicinal species.
\end{abstract}

\section{Introduction}

After the agreement of the Nagoya Protocol, which has highlighted the importance of traditional knowledge of local communities, interest has grown stronger regarding ethnomedicinal knowledge in the world [1]. Ethnomedicinal knowledge plays an extremely vital role in the health care systems of developing countries and is utilized as an alternative for the treatment of disorders without side effects in developed countries [2]. Investigations regarding ethnomedicinal knowledge in local communities have often been conducted to the indigenous communities of Asia, Africa, and South America.
At present, studies on the ethnomedicinal practices of local communities to treat specific disorders have been accomplished, including liver disease $[3,4]$, birth-related diseases [5, 6], uremia [7], diabetes [8], psychiatric disorders [9], ophthalmology [10], skin disorders [11], stomach issues $[11]$, veterinary medicine $[12,13]$, and other health conditions. However, research using INA on the ethnomedicinal practices to treat gastrointestinal disorders within local communities has yet to be accomplished.

Investigations for the ethnomedicinal practices of local communities to treat specific disorders in Korea have included respiratory diseases [14], digestive system disorders 
[15], and pain relief [16] for communities in North Jeolla Province.

National parks in Korea are areas designated to protect the representative ecosystem and the natural/cultural sceneries by the Ministry of Environment and are defined as natural areas of both land and sea. National parks are managed directly by the government and their purpose is to combine both a conservation and a sustainable use of the natural resources within the parks.

Designated as the first national park in 1967, Jirisan National Park spreads across one city and four counties and lies within three provinces. The total area of Jirisan National Park is $485 \mathrm{~km}^{2}$, which makes it the largest mountainous national park in Korea.

Hallasan National Park is located at the heart of Jeju Island, the largest and most beautiful island in Korea. Its total area is $1,849.18 \mathrm{~km}^{2}$ and is located at the southernmost tip of the nation.

Located in the deep inlands of southeastern Korea, Gayasan National Park spreads across one city and four counties and is located within two provinces. The total area of the park is $76.256 \mathrm{~km}^{2}$ and is known as the sacred site of Buddhism.

Accordingly, this research is the first attempt for comparing and analyzing ethnomedicinal practices to treat gastrointestinal disorders of communities in three national parks in Korea. However, up until now, a quantitative analysis for ethnomedicinal knowledge of local communities has relied solely on the consensus of its informants $[17,18]$ and the recorded fidelity levels [19-21].

These methods have limitations on the sufficient interpretation of ethnomedicinal knowledge as a complicated knowledge system embedded within the traditional ethnographical properties. Therefore, a deeper analysis of ethnomedicinal practices in treating specific disorders within the local communities is necessary for obtaining more specific details regarding the internetwork analysis (INA) between disorders and medicinal species.

This research suggests that the applications gained from utilizing the comparative INA for ethnomedicinal practices on gastrointestinal disorders within communities in three national parks will result in further research incorporating INA. The three study areas included in this study are Jirisan National Park (JNP), Gayasan National Park (GNP), and Hallasan National Park (HNP). These regions are included as typical inland and island areas of the southern region in Korea. Among the three national parks, the ethnomedicinal practices of the communities living within HNP were investigated in regard to both medicinal plants [22] and medicinal animals [23].

The results of this study can be utilized to develop functional foods, pharmafoods, and new ethnomedicinal practices for gastrointestinal disorders in these communities and other regions within Korea.

\section{Research Area and Method}

2.1. Natural and Social Environments of Research Area. The study area consists of the southern region of the Korean peninsula and its many islands, which lie between $33^{\circ} 06^{\prime} \mathrm{N}$ to $36^{\circ} 09^{\prime} \mathrm{N}$ latitude and $125^{\circ} 58^{\prime} \mathrm{E}$ to $128^{\circ} 18^{\prime} \mathrm{E}$ longitude (Figure 1). The total population in 2012 of the study area was $1,161,002$. The area measures approximately $2,410,434 \mathrm{~km}^{2}$ and includes five provinces, four cities, and eight counties in its administrative district [24]. The annual precipitation is around $1,200 \sim 2,300 \mathrm{~mm}$ in which the coastal area generally receives more rainfall than the inland regions. The annual average temperature of the inland regions is $13^{\circ} \mathrm{C}$, while Jeju Island records $16.2^{\circ} \mathrm{C}$ [25]. The natural and social environments of the three national parks are summarized in Table 1.

2.2. Investigative Method. Field investigations were conducted from March 2009 to November 2012. Proper data was collected using participant observations and indepth interviews, as the informants also became investigators themselves through attending informal meetings, open and group discussions, and overt observations with semistructured questionnaires [21, 26].

The content of the semistructured questionnaires was composed of diverse information regarding medicinal species used to treat gastrointestinal disorders, including local names, used parts, methods of preparation, manufacturing and administration, dosage, and the usable duration regarding each curable formula $[21,27,28]$.

All specimens were collected during their flowering or fruiting seasons and were organized utilizing the normal specimen manufacturing method [20, 27]. The voucher specimens were deposited for preservation in the herbarium of Jeonju University. The precise identification of species mentioned by the informants was performed in accordance with Lee [29], Lee [30], Ahn [31], Lee [32], and Park [33]. Scientific names were confirmed by the National Knowledge and Information System for Biological Species of Korea [34].

\subsection{Quantitative Analysis}

2.3.1. Informant Consensus Factor (ICF). The ICF was used to analyze the agreement degree of the informants' knowledge about each category of disorders [17, 18]. The ICF was calculated using the following formula:

$$
\mathrm{ICF}=\frac{\left(n_{u r}-n_{t}\right)}{\left(n_{u r}-1\right)},
$$

where $n_{u r}$ is the number of use reports of informants for a particular gastrointestinal disorder and $n_{t}$ is the number of species used by all informants for a particular gastrointestinal disorder.

2.3.2. Fidelity Level ( FL). The FL was employed to determine the most important species used for treating certain gastrointestinal disorders by the local practitioners and the elderly people living in the study area [19-21]. The FL was calculated using the following formula:

$$
\mathrm{FL}(\%)=N_{p} \times \frac{100}{N},
$$



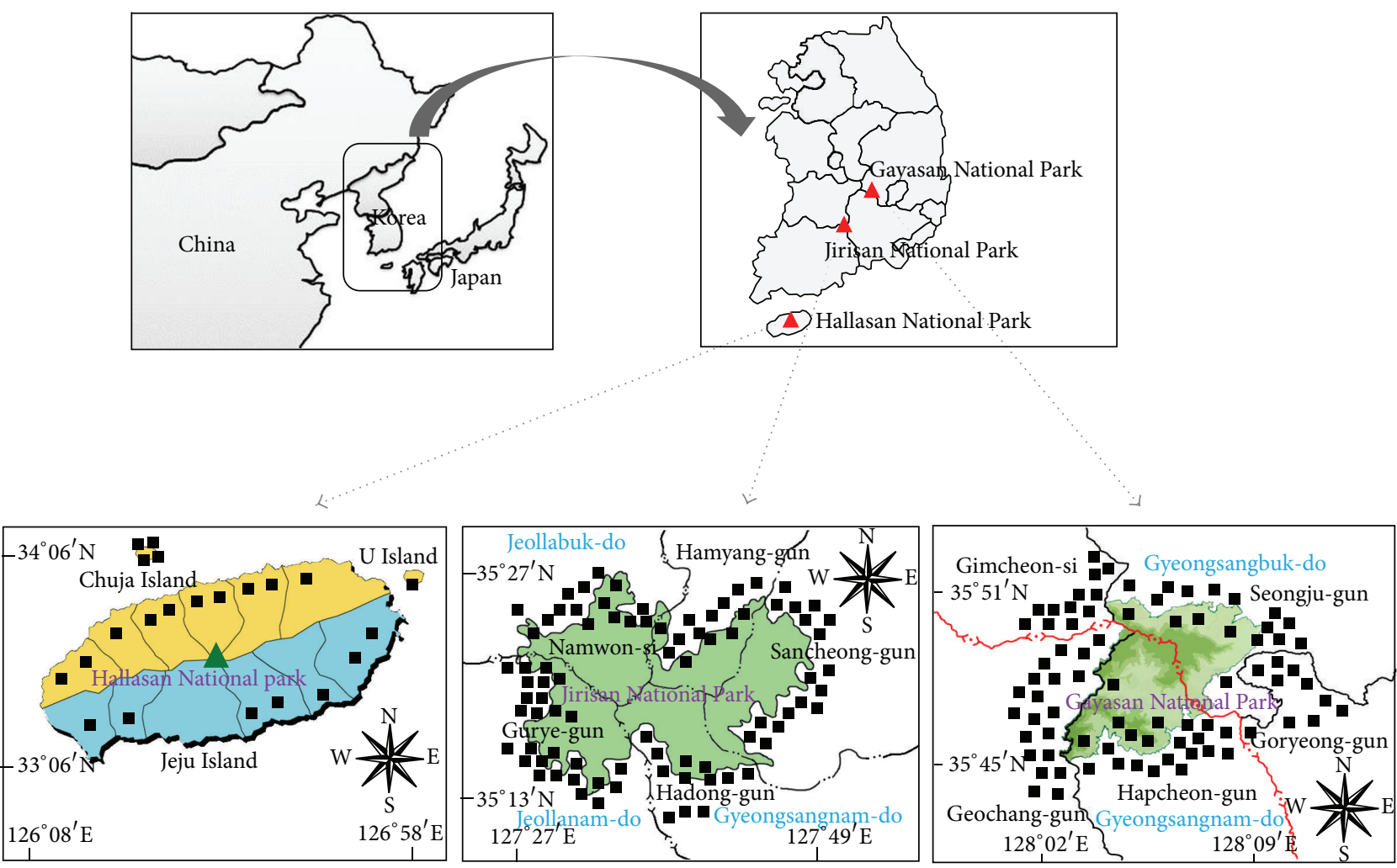

FIGURE 1: Investigation sites.

TABLE 1: Natural and social environments of three national parks.

\begin{tabular}{|c|c|c|c|}
\hline Environment & JNP & GNP & HNP \\
\hline Location & $\begin{array}{c}35^{\circ} 13^{\prime} \mathrm{N} \sim 33^{\circ} 27^{\prime} \mathrm{N} \\
127^{\circ} 27^{\prime} \mathrm{E} \sim 127^{\circ} 49^{\prime} \mathrm{E}\end{array}$ & $\begin{array}{l}35^{\circ} 45^{\prime} \mathrm{N} \sim 35^{\circ} 49^{\prime} \mathrm{N} \\
128^{\circ} 02^{\prime} \mathrm{E} \sim 128^{\circ} 09^{\prime} \mathrm{E}\end{array}$ & $\begin{array}{l}33^{\circ} 06^{\prime} \mathrm{N} \sim 34^{\circ} 00^{\prime} \mathrm{N} \\
126^{\circ} 08^{\prime} \mathrm{E} \sim 126^{\circ} 58^{\prime} \mathrm{E}\end{array}$ \\
\hline Administrative district & $\begin{array}{l}\text { Three provinces, one } \\
\text { city, and four counties }\end{array}$ & $\begin{array}{l}\text { Two provinces, one city, } \\
\text { and four counties }\end{array}$ & $\begin{array}{c}\text { One province and two } \\
\text { cities }\end{array}$ \\
\hline Population (no.) & 241,784 & 335,934 & 583,284 \\
\hline Area & $485 \mathrm{~km}^{2}$ & $76.256 \mathrm{~km}^{2}$ & $1,849.18 \mathrm{~km}^{2}$ \\
\hline Annual precipitation & $1,200 \sim 1,600 \mathrm{~mm}$ & $1,200 \sim 1,600 \mathrm{~mm}$ & $1,584 \sim 2,393 \mathrm{~mm}$ \\
\hline $\begin{array}{l}\text { Annual average } \\
\text { temperature }\end{array}$ & $12^{\circ} \mathrm{C} \sim 14^{\circ} \mathrm{C}$ & $11^{\circ} \mathrm{C} \sim 13.2^{\circ} \mathrm{C}$ & $15.6 \sim 16.9^{\circ} \mathrm{C}$ \\
\hline $\begin{array}{l}\text { Geographical } \\
\text { characteristics }\end{array}$ & $\begin{array}{l}\text { The center of the } \\
\text { southern region of Korea }\end{array}$ & $\begin{array}{c}\text { The southern region of } \\
\text { Korea }\end{array}$ & $\begin{array}{l}\text { The largest volcanic } \\
\text { island in Korea }\end{array}$ \\
\hline $\begin{array}{l}\text { Climatic zone of } \\
\text { vegetation }\end{array}$ & \multicolumn{2}{|c|}{ Between a warm temperate zone and a subarctic zone } & $\begin{array}{l}\text { Between a warm } \\
\text { temperature } \\
\text { zone to an alpine or } \\
\text { arctic zone }\end{array}$ \\
\hline
\end{tabular}

*JNP: Jirisan National Park, GNP: Gayasan National Park, HNP: Hallasan National Park.

where $N_{p}$ is the number of informants that mentioned the specific species used to treat certain disorders and $N$ is the total number of the informants who utilized the species as medicine for treating any given disorder.

2.3.3. Internetwork Analysis (INA). Internetwork analysis does not focus on the independent characteristics of an individual within the community but considers the results of the interrelationship among each individual of a community. INA has been applied within communities for various ethnographical problems, including ethnogenesis [35] and obesity [36-38]. However, the INA had yet to be applied to ethnomedicinal knowledge, although it has been included in relation to its ethnographical properties. 
TABLE 2: Ethnographical characteristics of three national parks.

\begin{tabular}{|c|c|c|c|}
\hline Characteristics & JNP & GNP & HNP \\
\hline \multicolumn{4}{|l|}{ Gender } \\
\hline Male & $67(34.9 \%)$ & $36(15.6 \%)$ & $31(36.5 \%)$ \\
\hline Female & $125(65.1 \%)$ & $195(84.4 \%)$ & $54(63.5 \%)$ \\
\hline Average age & $72.9(44 \sim 95)$ & $76.8(52 \sim 93)$ & $78.4(43 \sim 94)$ \\
\hline \multicolumn{4}{|l|}{ Educational attainment } \\
\hline Never attended school & $138(71.9 \%)$ & $165(71.4 \%)$ & $62(72.9 \%)$ \\
\hline Attended school & $54(28.1 \%)$ & $66(28.6 \%)$ & $23(27.1 \%)$ \\
\hline Linguistics & \multicolumn{2}{|c|}{$\begin{array}{l}\text { The pronunciation between the eastern and } \\
\text { western communities on the Jirisan axis } \\
\text { depicts dissimilar intonations. }\end{array}$} & $\begin{array}{l}\text { Numerous dialects } \\
\text { different from the inland } \\
\text { communities. }\end{array}$ \\
\hline Food & \multicolumn{2}{|c|}{$\begin{array}{l}\text { The local communities in the eastern region } \\
\text { of Jirisan widely used the seed powder of } \\
\text { Zanthoxylum piperitum (L.) DC. and the } \\
\text { leaves of the Isodon japonicus (Burm.) Hara, } \\
\text { while local communities in the western } \\
\text { region did not consume these foods. }\end{array}$} & $\begin{array}{l}\text { Quite diverse from foods } \\
\text { of the inland } \\
\text { communities in regard } \\
\text { to the recipe and } \\
\text { ingredients. }\end{array}$ \\
\hline Home economy & \multicolumn{2}{|c|}{$\begin{array}{l}\text { Men usually support their families } \\
\text { financially. }\end{array}$} & $\begin{array}{l}\text { Women traditionally } \\
\text { support their families. }\end{array}$ \\
\hline
\end{tabular}

Our research has newly applied this method in order to attain more internetwork information from the treatment of ethnomedicinal practices on gastrointestinal disorders within communities in Korea. The results of the INA of disorders and medicinal species were analyzed using UCINET (Ver. 6.460) and NetDraw (Ver. 2.125) software programs [39, 40].

\section{Results and Discussion}

3.1. Ethnographic Characteristics of the Region. The ethnomedicinal practices for gastrointestinal disorders were recorded by 507 informants (133 men and 374 women) at 185 sites (Figure 1). The average age of the informants was 76 years, with a range in age from 43 to 95, with residents living more than 30 years in the study area. The ethnographical characteristics of the communities are summarized in Table 2.

3.2. Analysis of Ethnomedicinal Practices. 24 types of gastrointestinal disorders were treated by ethnomedicinal practices, which included abdominal pain, acute gastroenteritis, constipation, and other conditions (Table 3). The 24 types recorded in this study were similar to previous research, which classified 14 types of respiratory system diseases, 29 types of digestive system diseases, and 23 types of pain relief treatments [14, 16, 21]. Among them, 20 types of disorders were recorded in the communities living within JNP, followed by the 16 types of disorders within HNP, and the 11 types of disorders in GNP (Table 4).

A total of 490 ethnomedicinal practices recorded from the communities were classified into 110 families, 176 genera, and 220 species that included plants, animals, fungi, and alga (Table 4). Among these species, plants totaled 361 ethnomedicinal practices based on 142 species, while animals included 119 ethnomedicinal practices based on 71 species.
Fungi recorded 9 ethnomedicinal practices based on six species while alga included one ethnomedicinal practice based on one species. These usage patterns were different from Korean traditional medicine, in which plants are used relatively much more than animals. Research confirms that communities have focused on the functional supplements from these ethnomedicinal practices rather than seeking after an actual cure for their gastrointestinal disorders.

The residents of these communities have applied the ethnomedicinal practices for gastroenteric trouble and indigestion more than any other disorder. Namely, the number of medicinal species and ethnomedicinal practices for gastroenteric trouble consisted of 94 species $(42.7 \%$ of the total species) and 179 ethnomedicinal practices (36.5\% of the total practices). Indigestion used 72 species $(32.7 \%$ of the total species) and 131 ethnomedicinal practices $(26.7 \%$ of the total practices) (Table 5).

Also, the number of informants who mentioned gastroenteric trouble and cases of indigestion occupied $28.9 \%$, which totaled $30.0 \%$ of the whole, respectively (Table 5). As a result, the communities tended to use ethnomedicinal practices to care for their overall health instead of as a cure for a long-term condition.

For plants, 29 used parts were used in practice, while 14 used parts of animals and one used part of fungi and alga were used in treatment. Preparations of the plants consisted of 41 kinds, with 16 preparations for animals, six preparations for fungi, and one preparation for alga (Table 4). These usage patterns are similar to previous research for other diseases [14-16].

\subsection{Quantitative Analysis}

3.3.1. Informant Consensus Factor (ICF). The informant consensus factor ranges from 0 to 1 , where the increasing values 


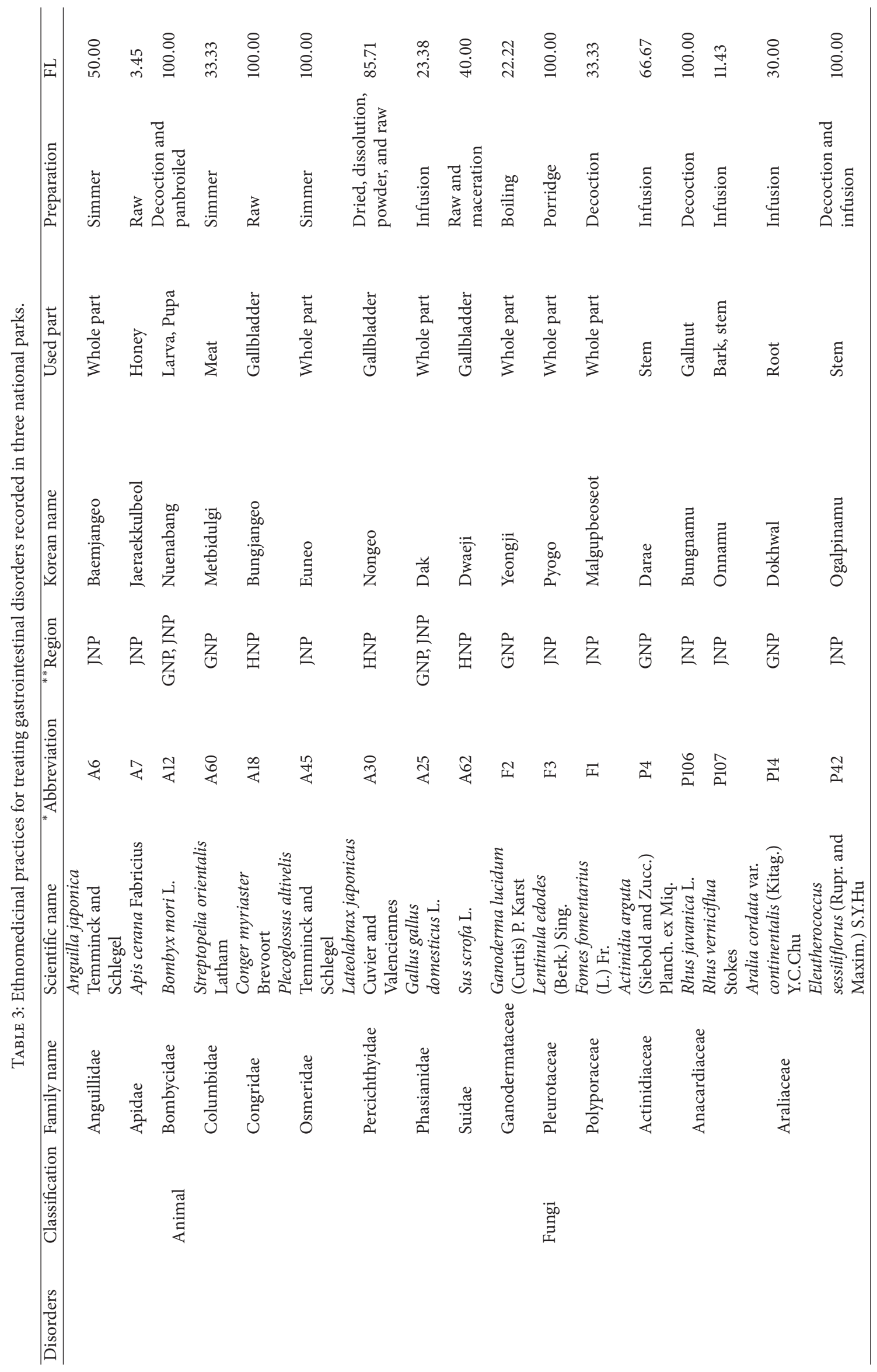




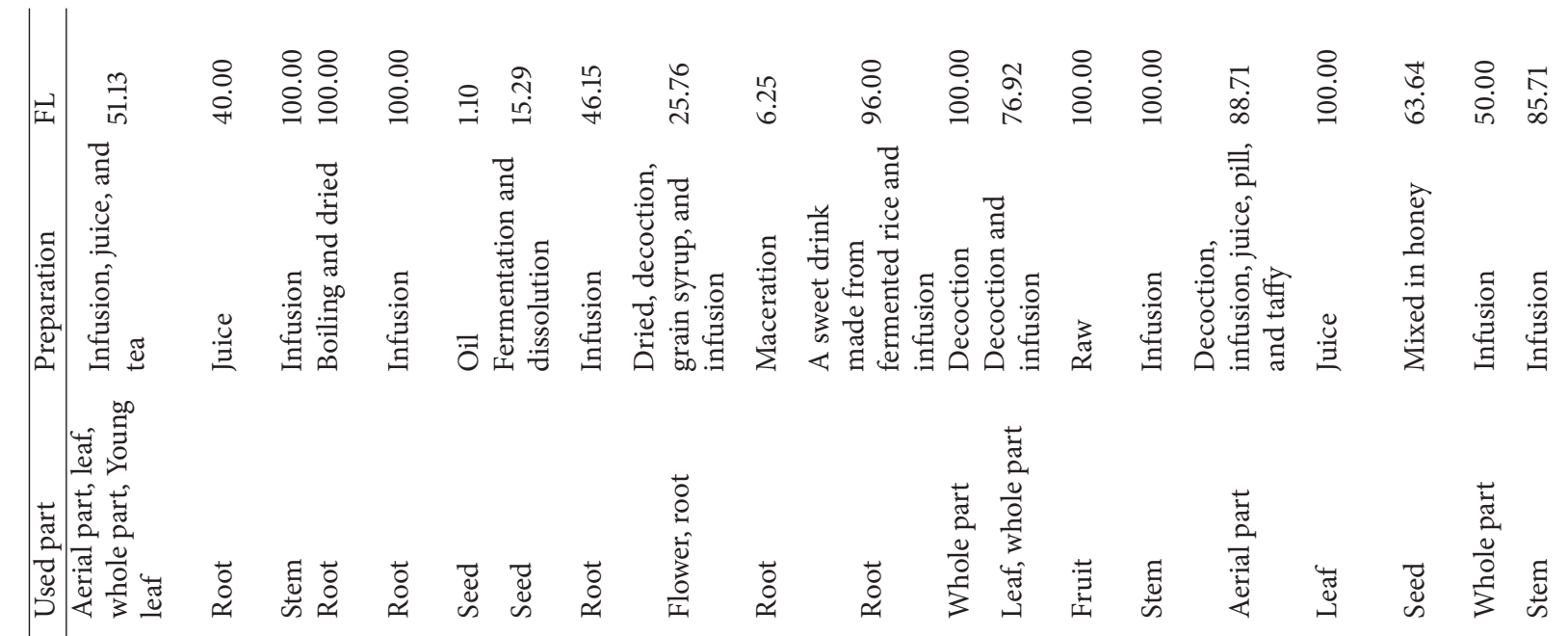

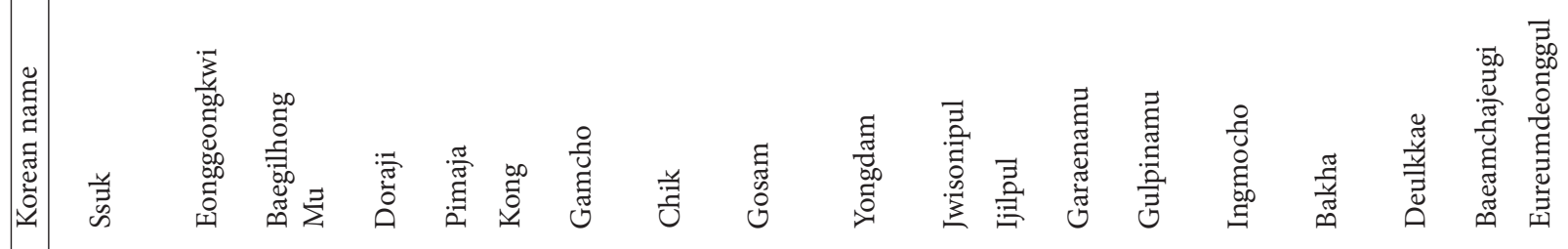

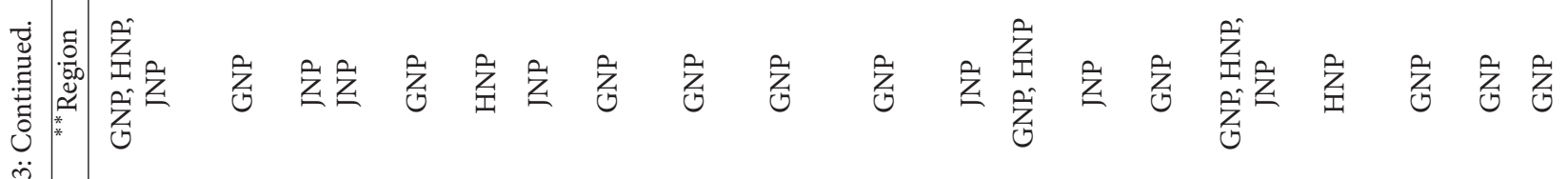

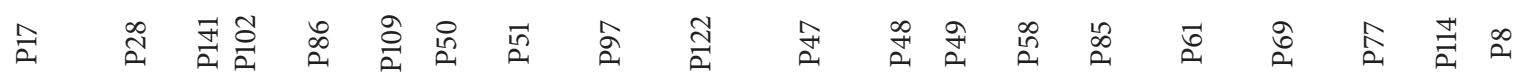

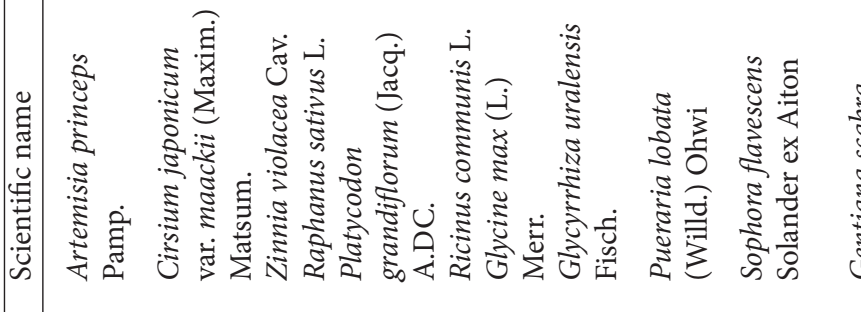
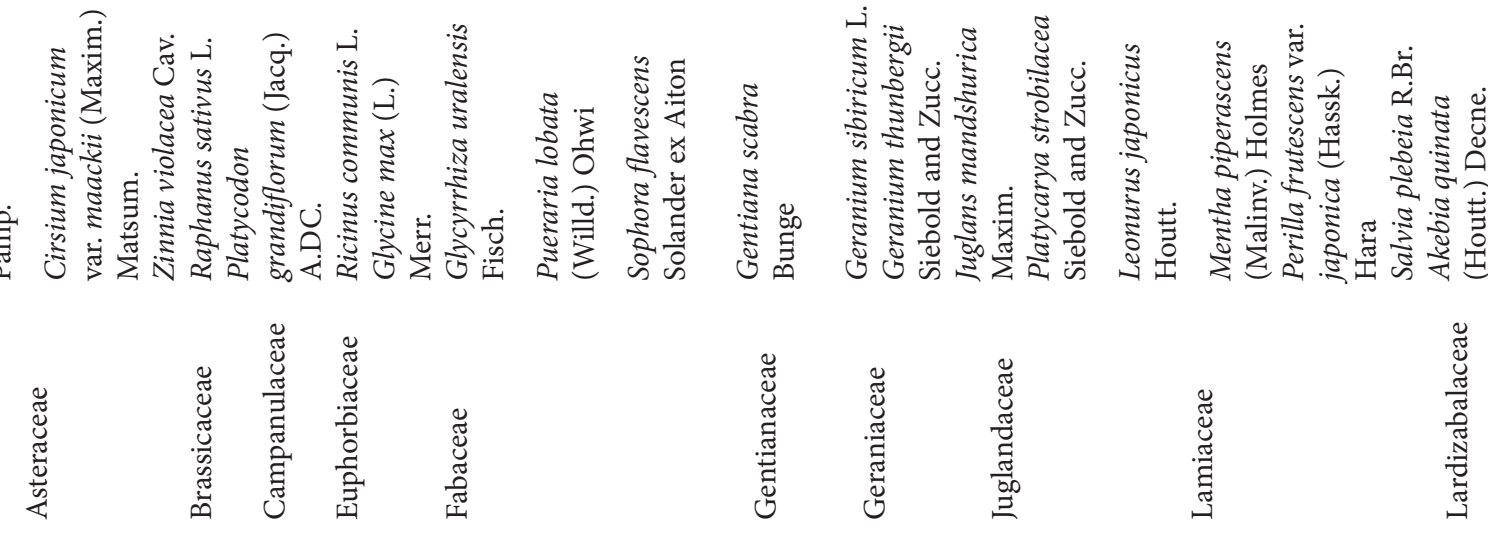


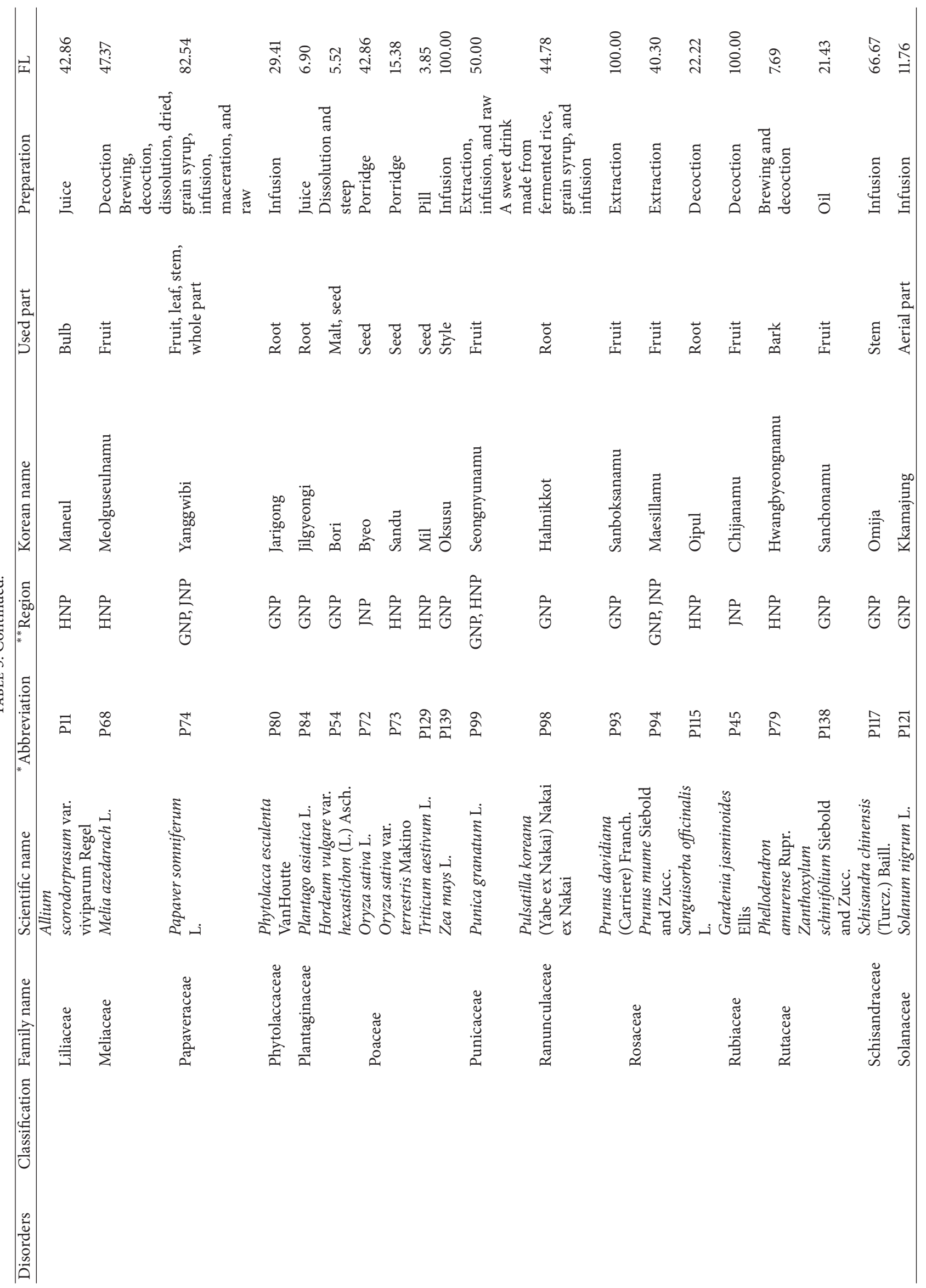




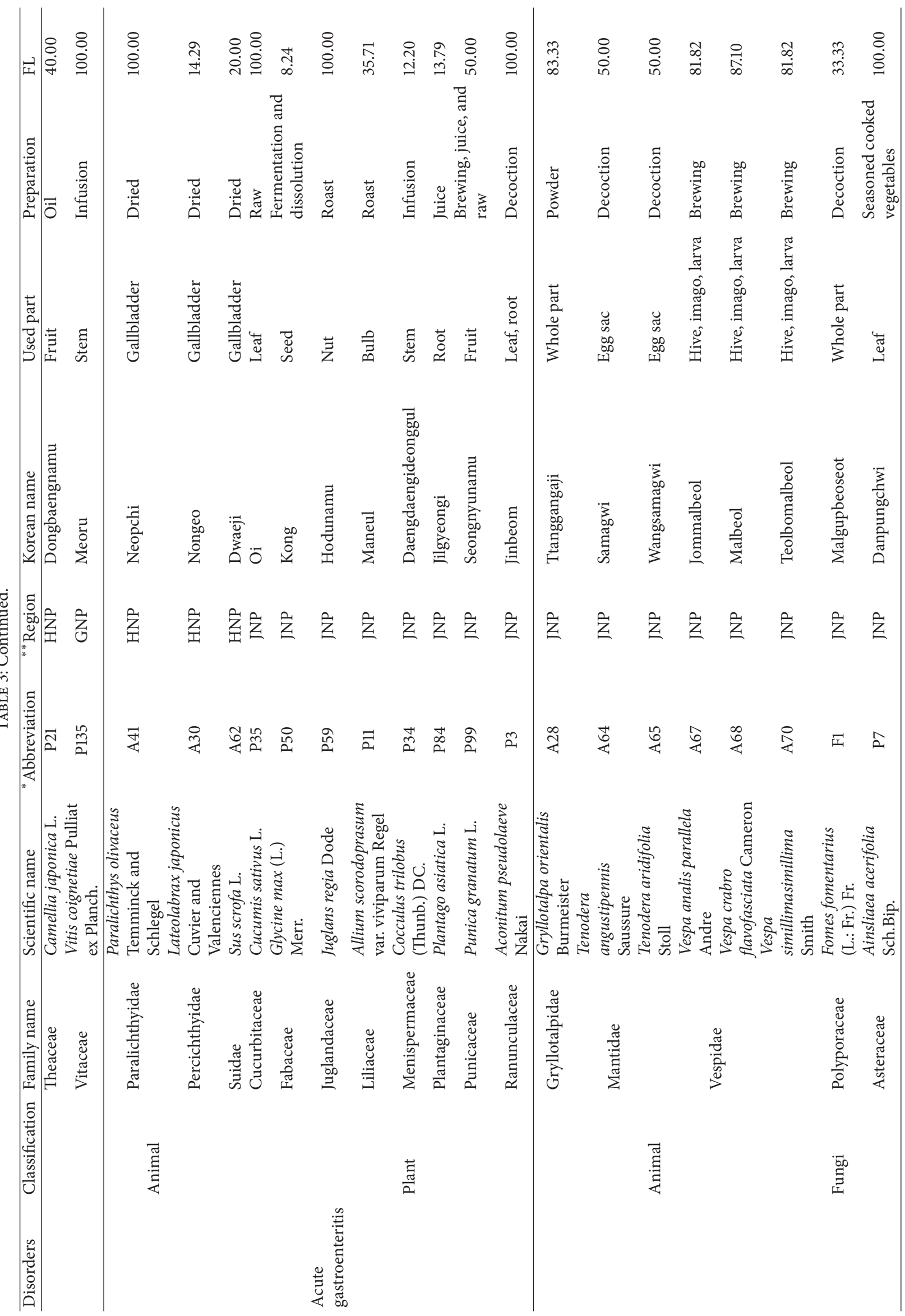




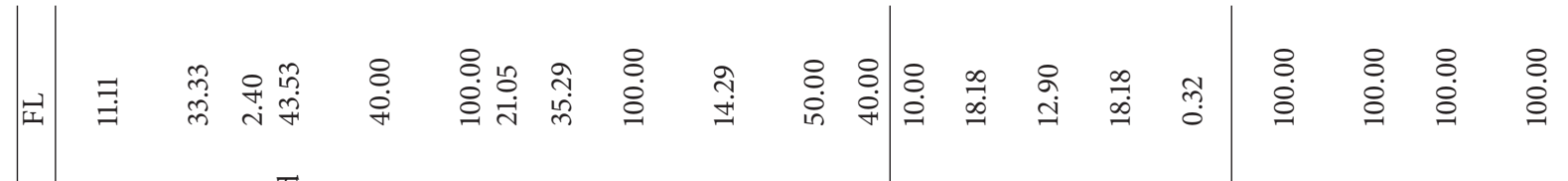

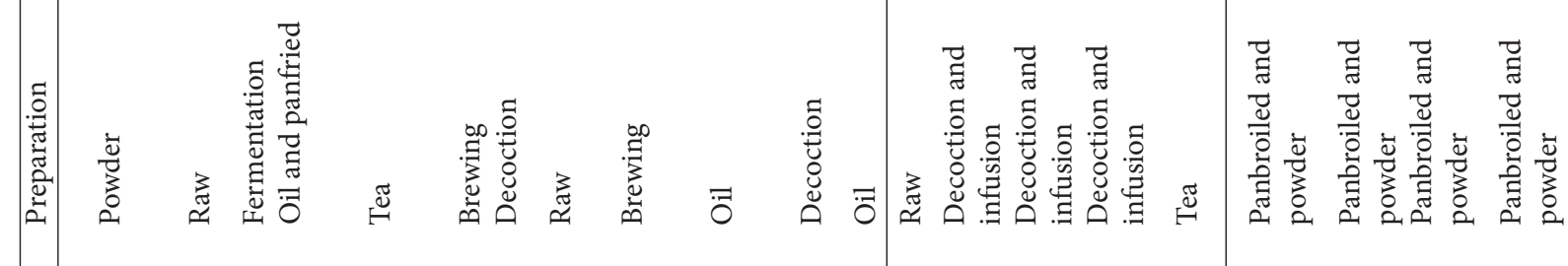

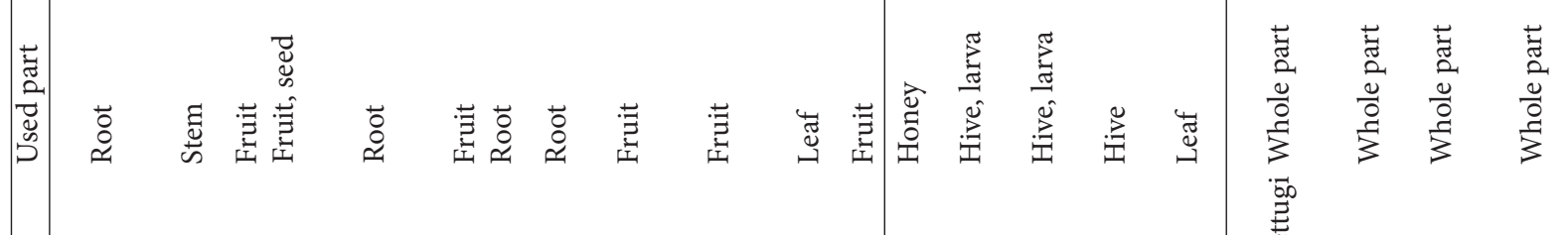

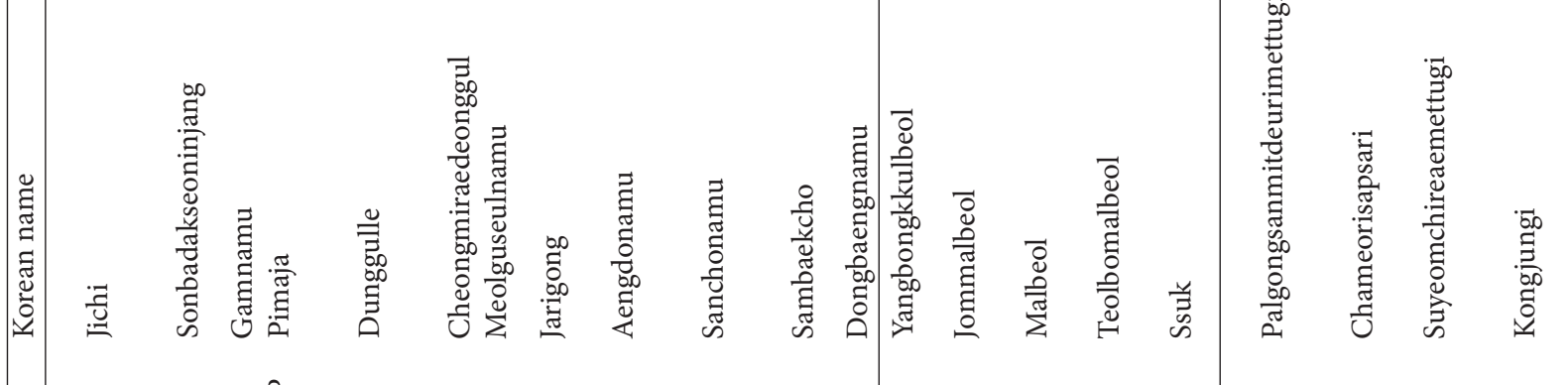

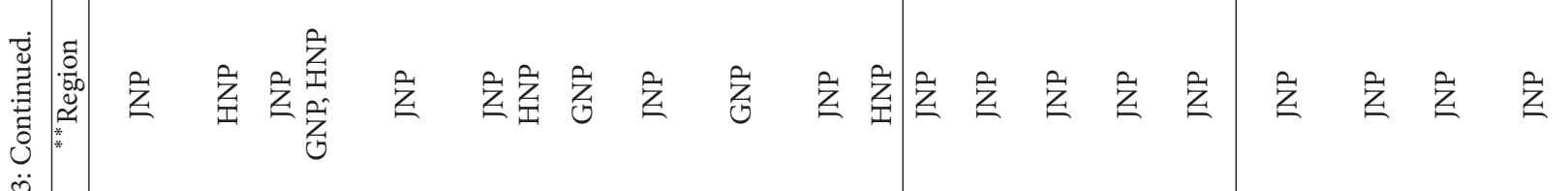

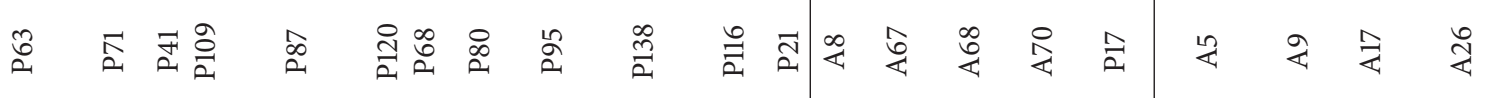

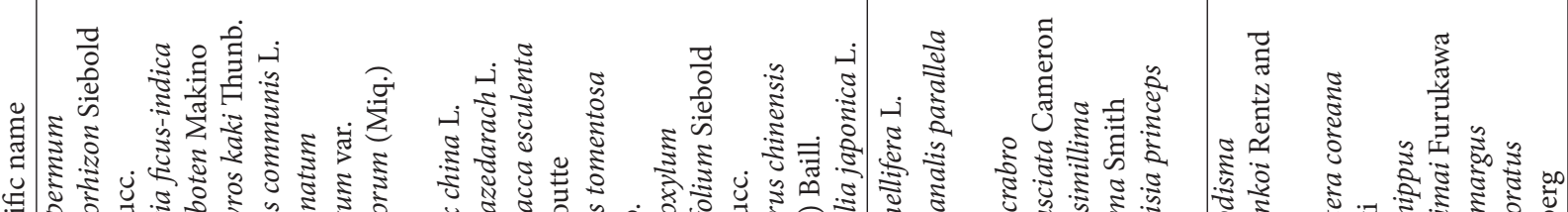

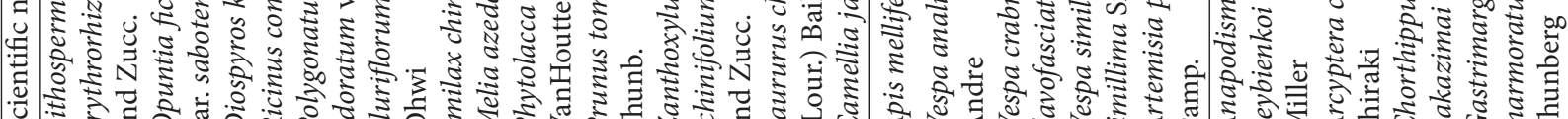

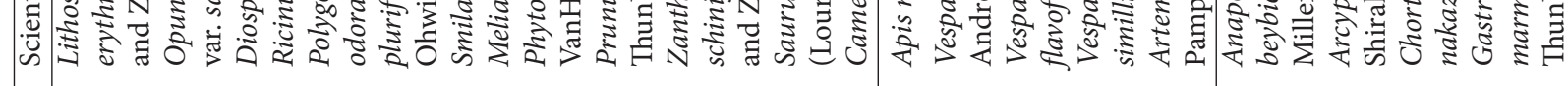

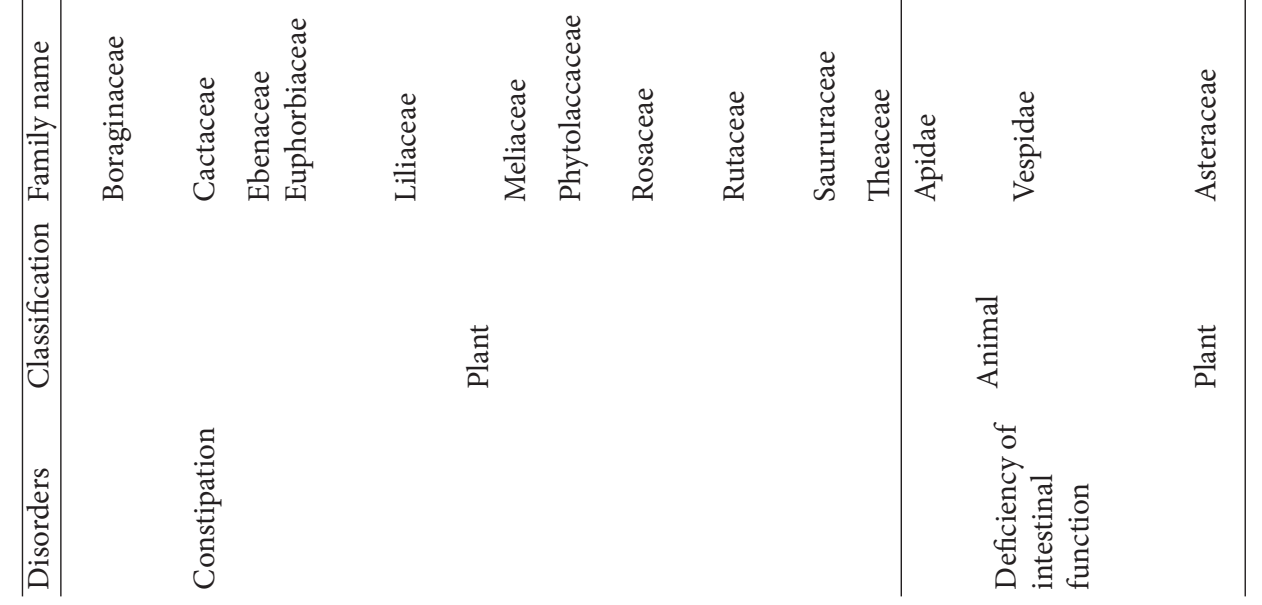

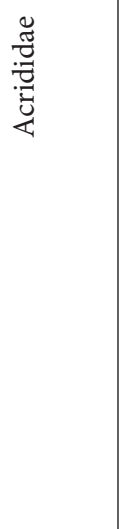




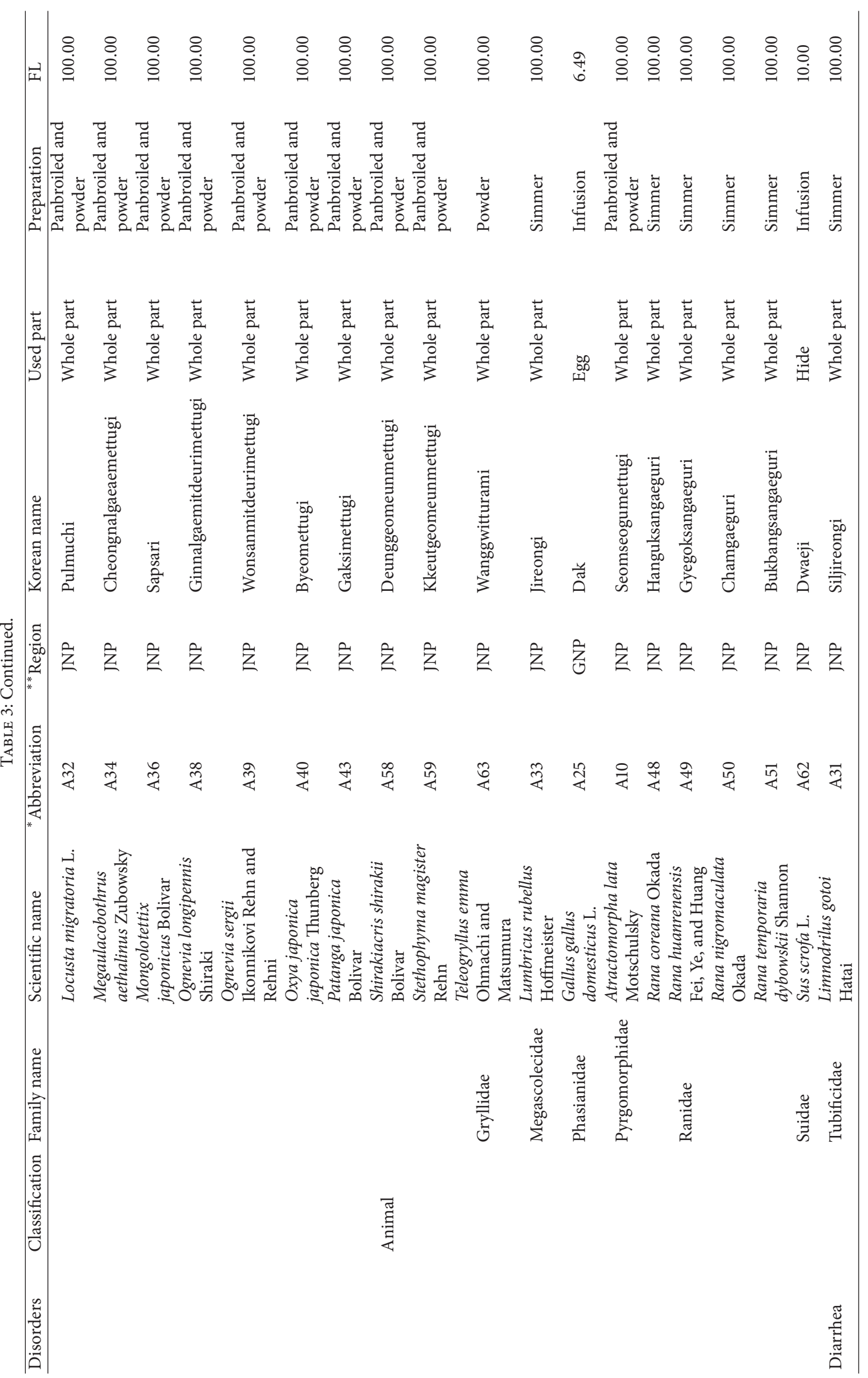




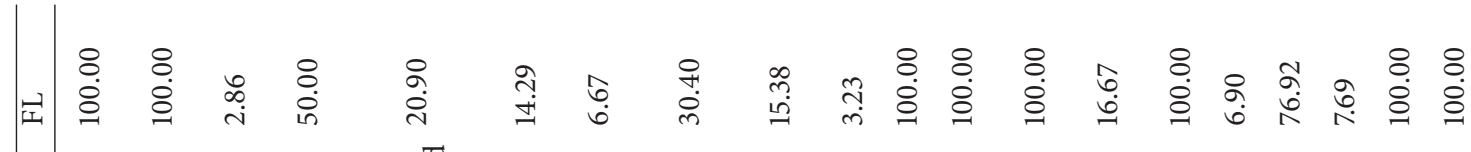

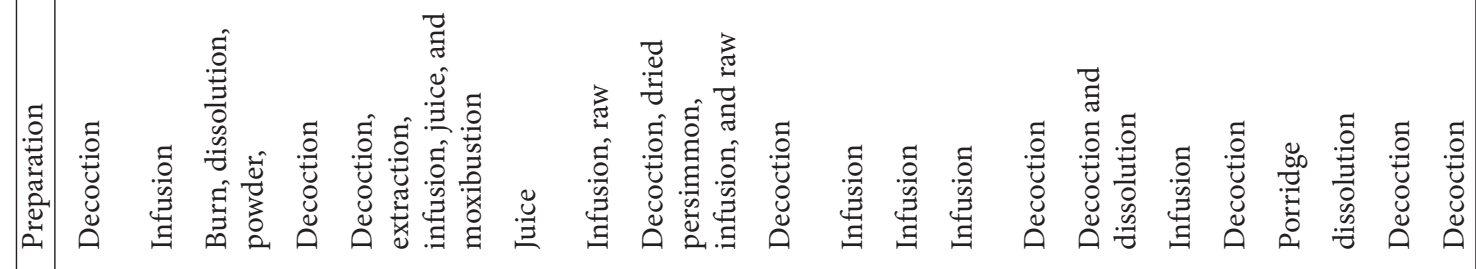

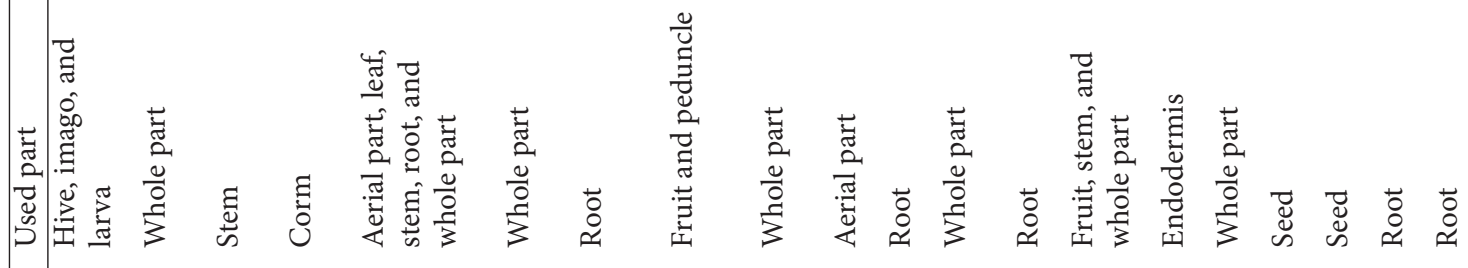

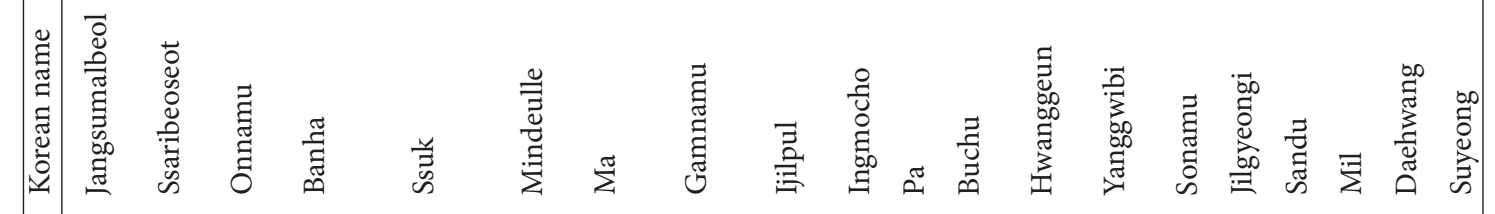

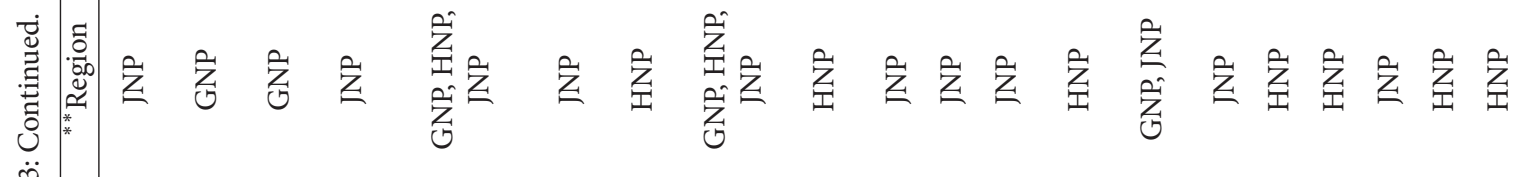
番

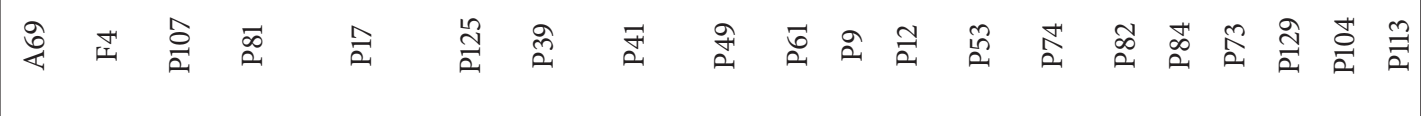

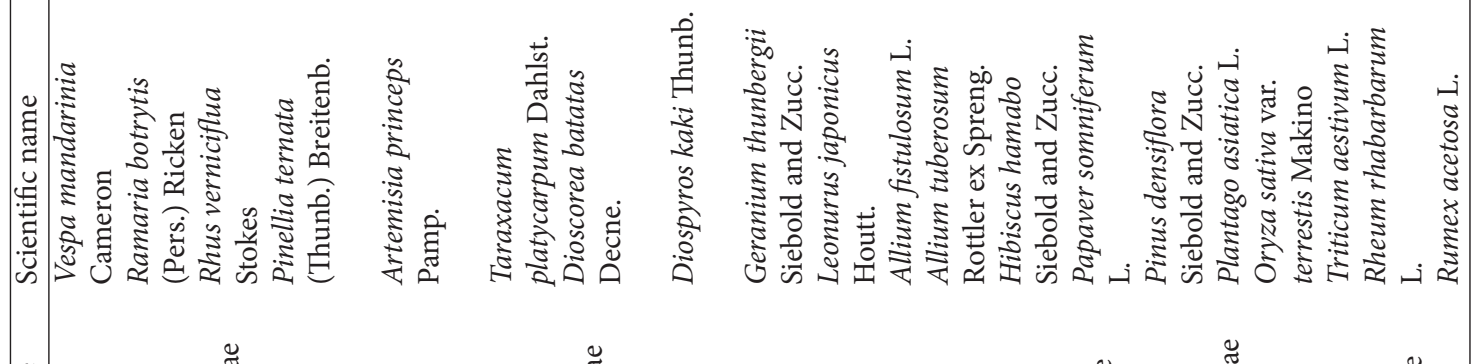

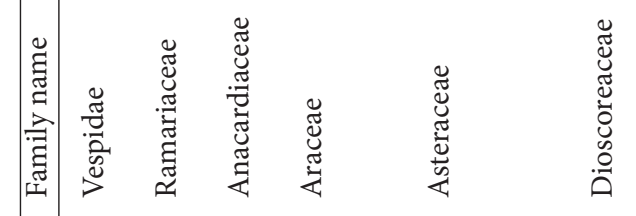

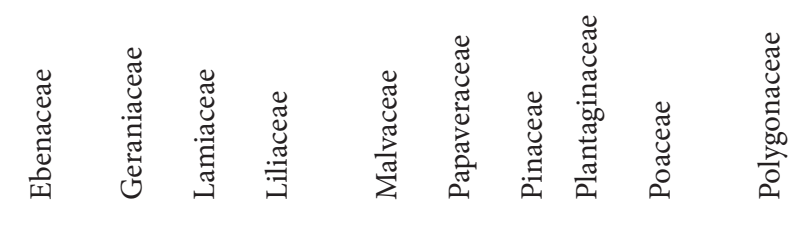
$\underset{50}{\stackrel{50}{\Xi}}$ 


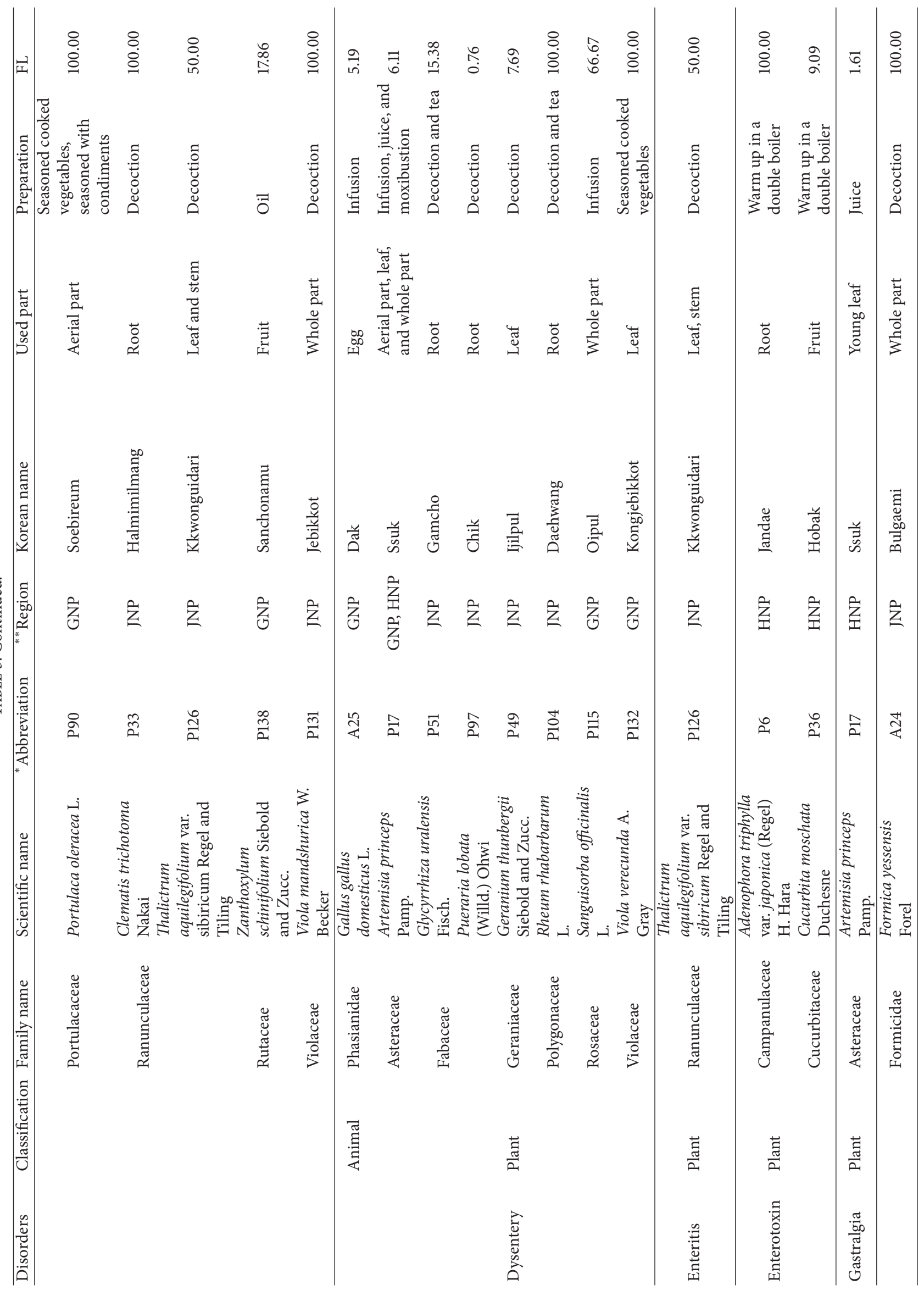




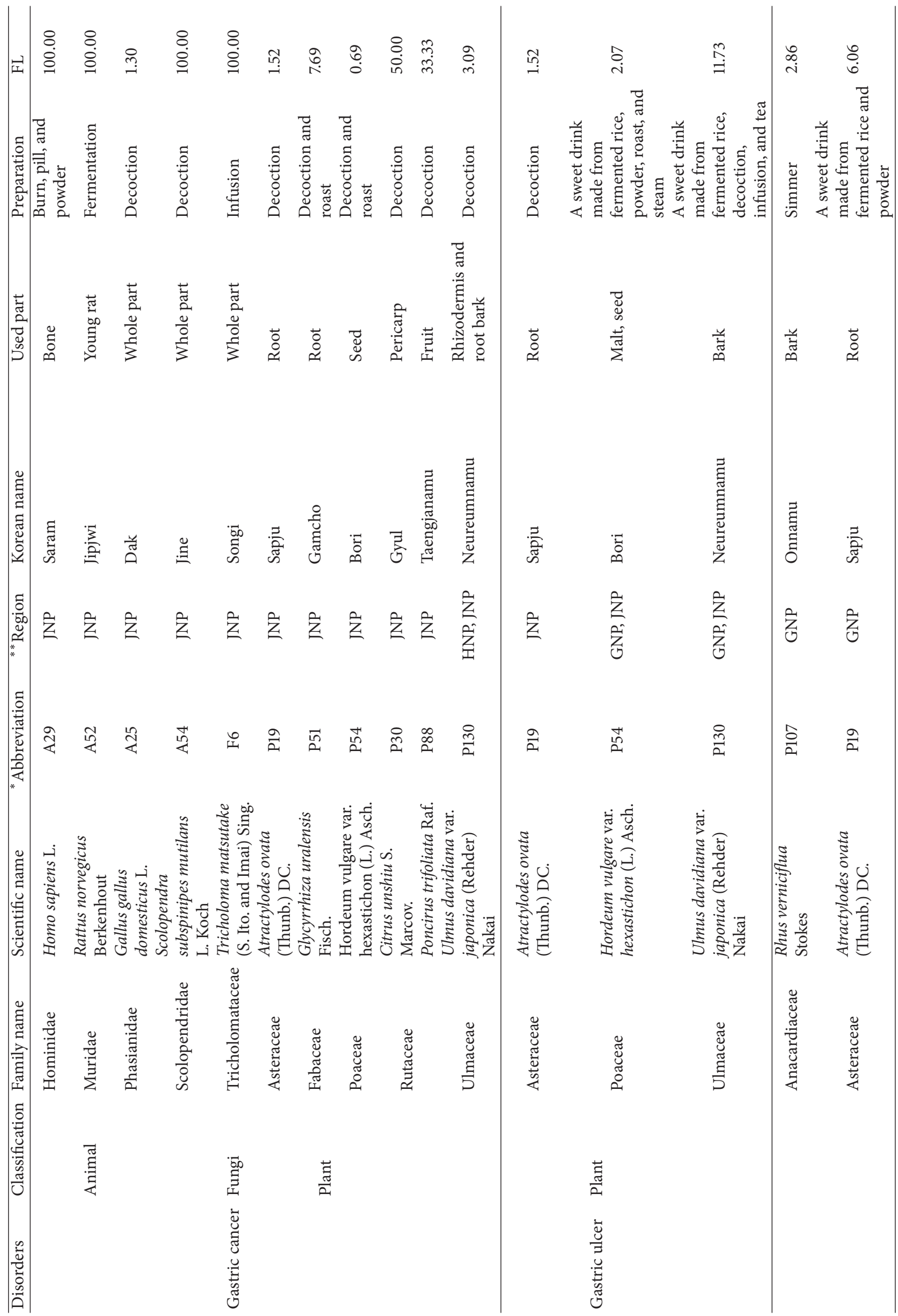




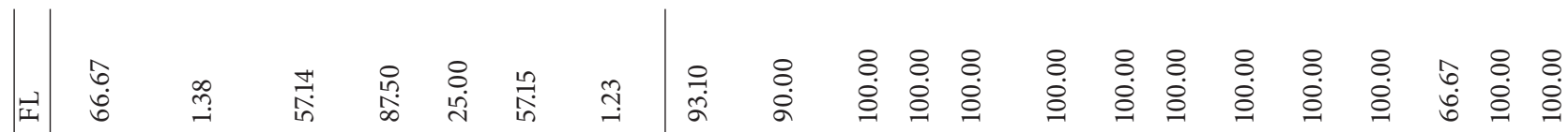

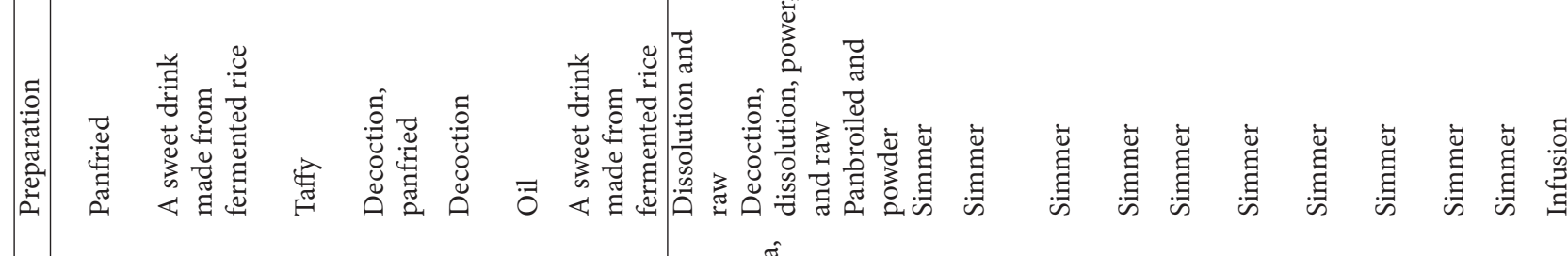

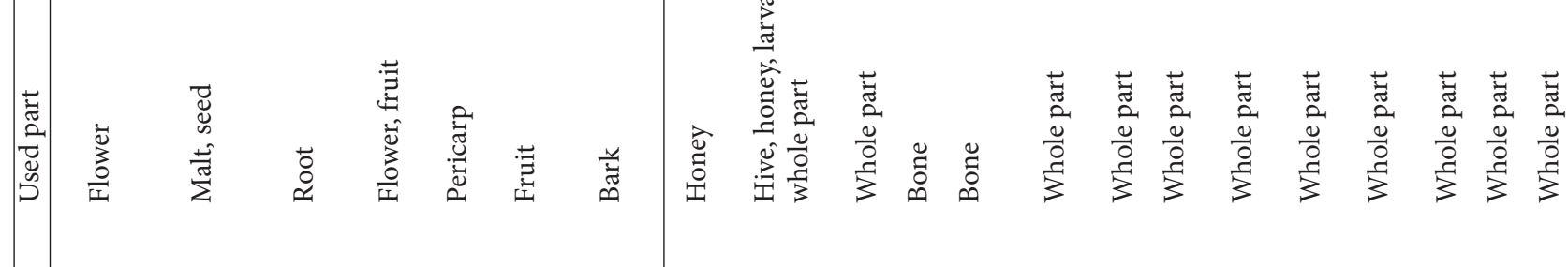

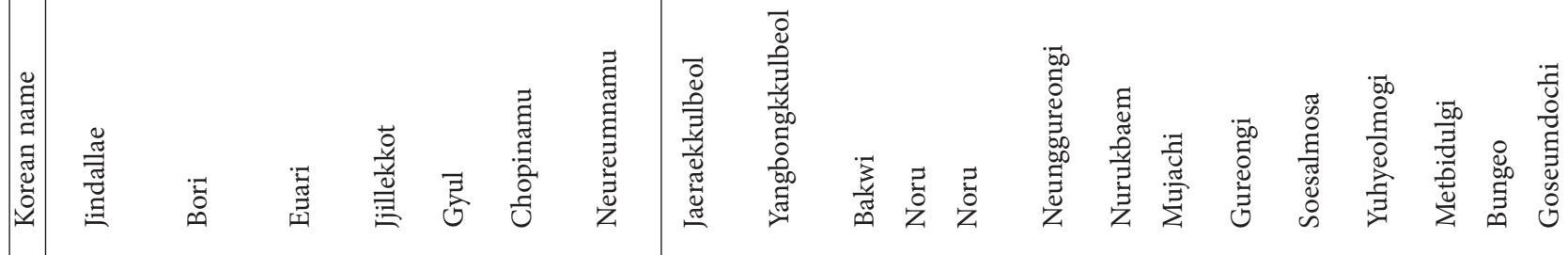

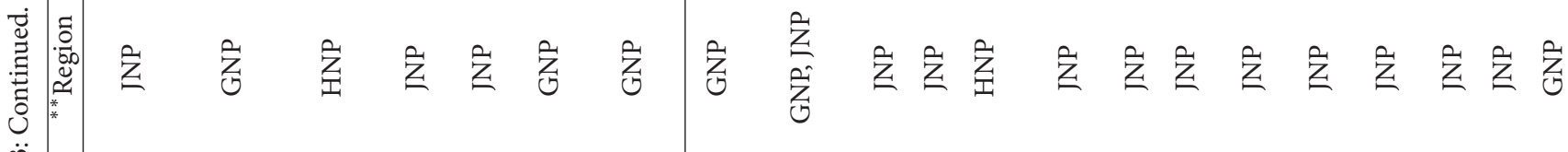

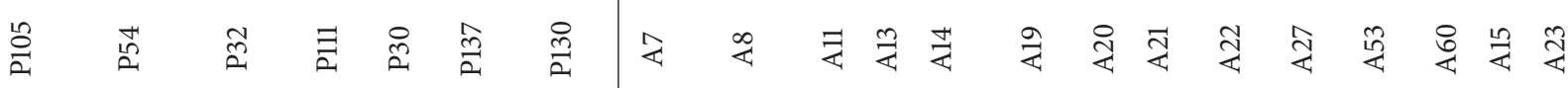

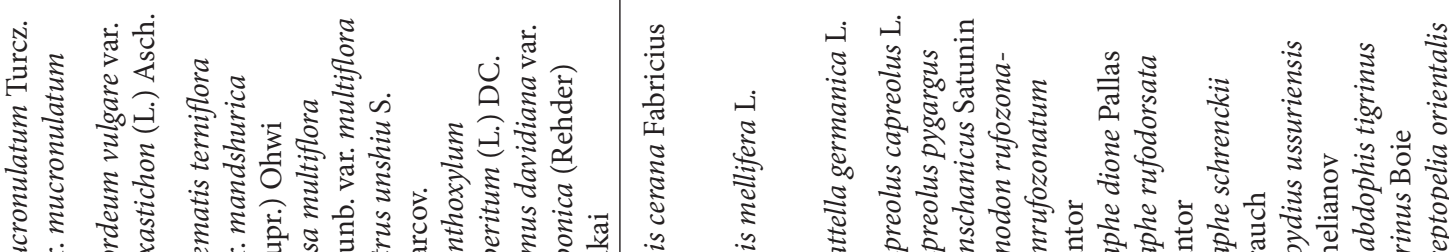

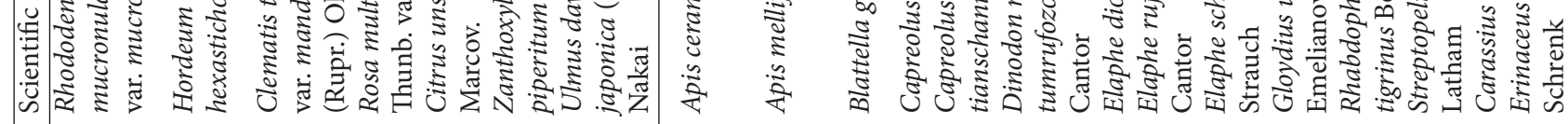

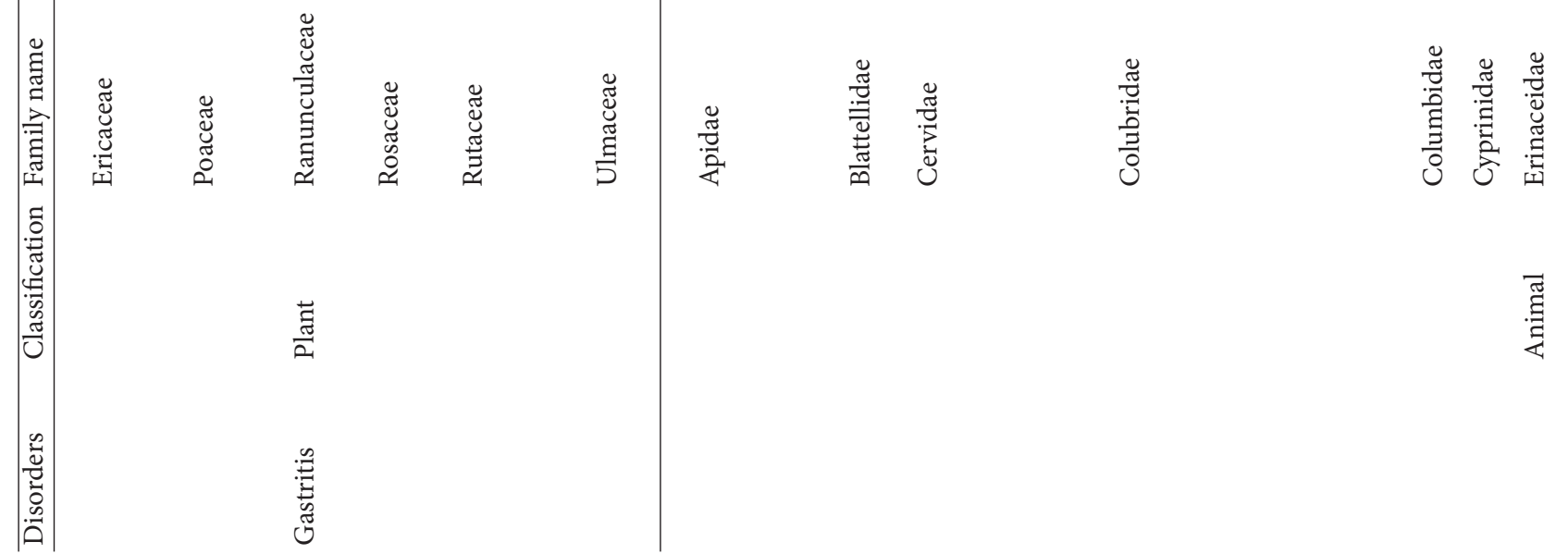




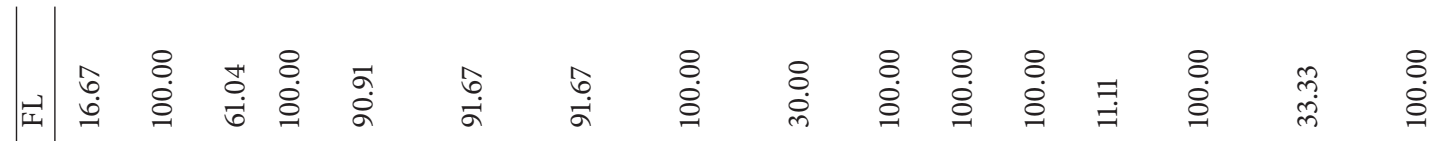

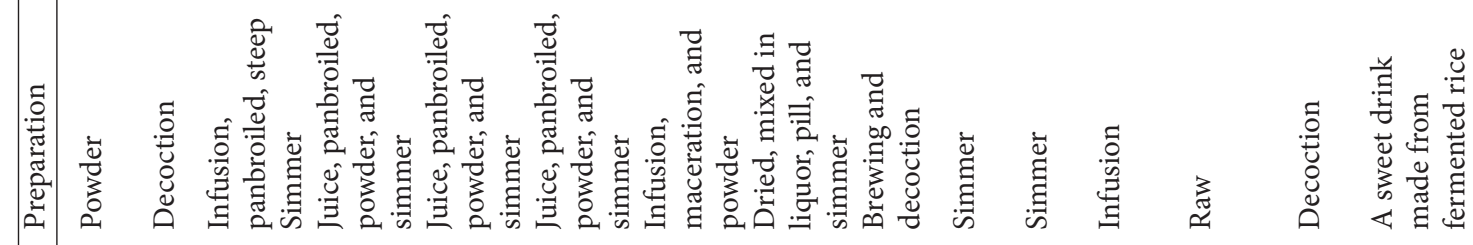

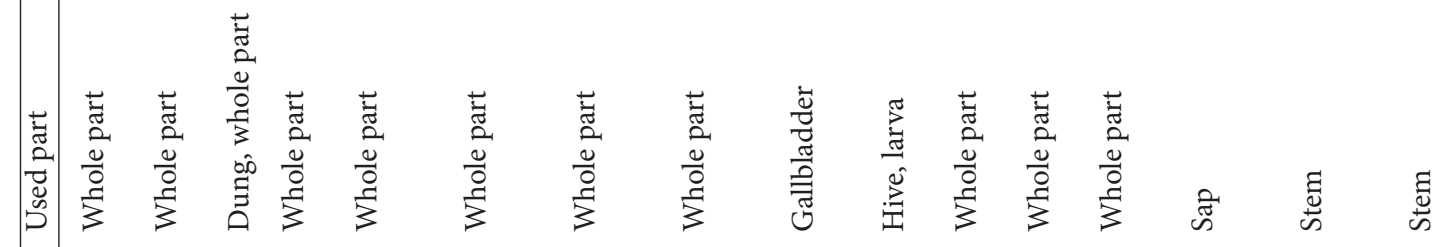

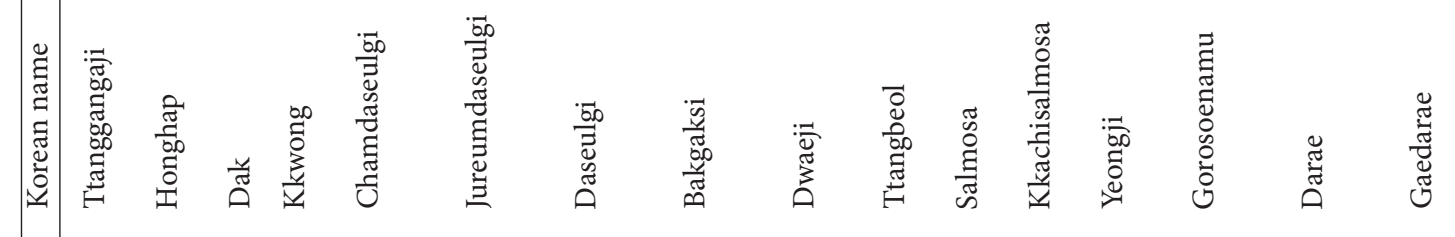

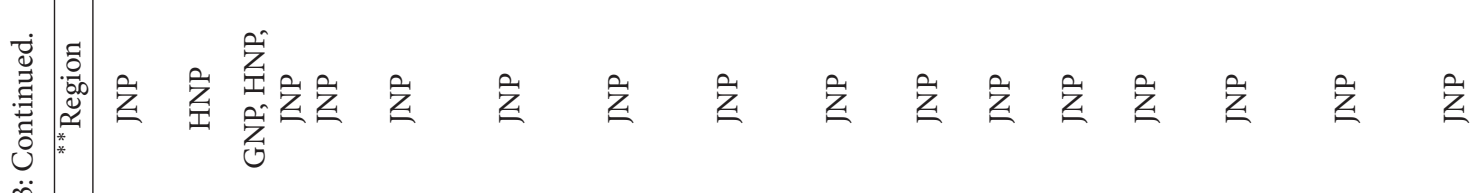
䍠

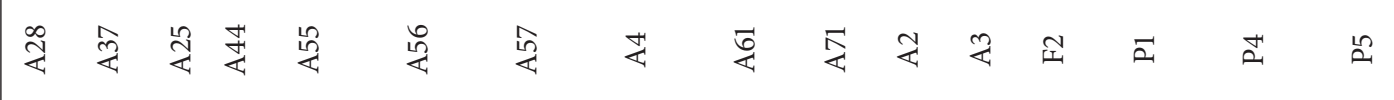

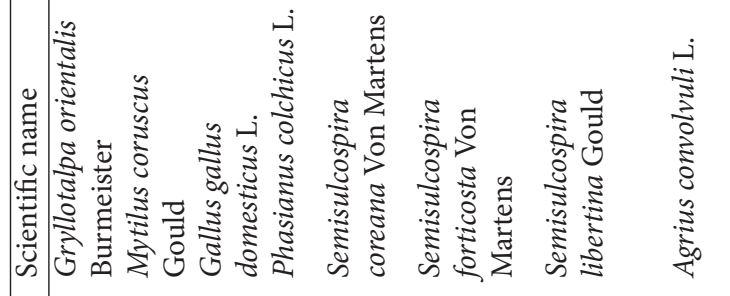

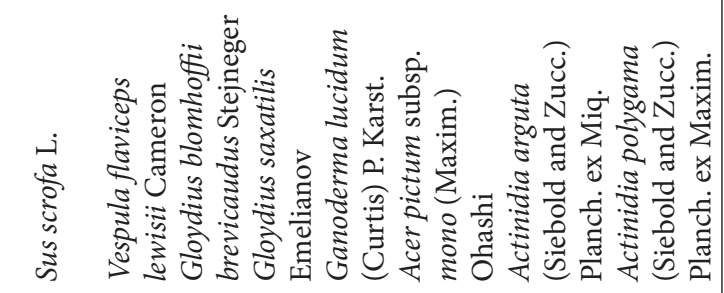

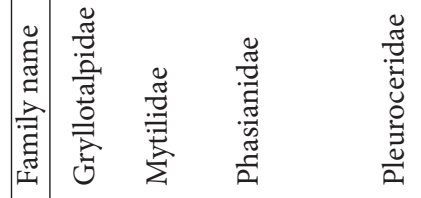

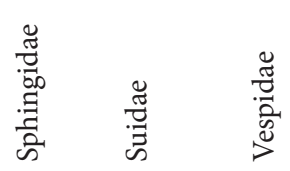

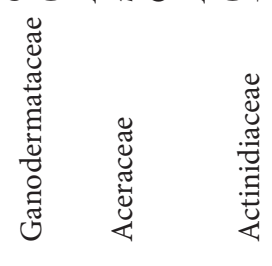




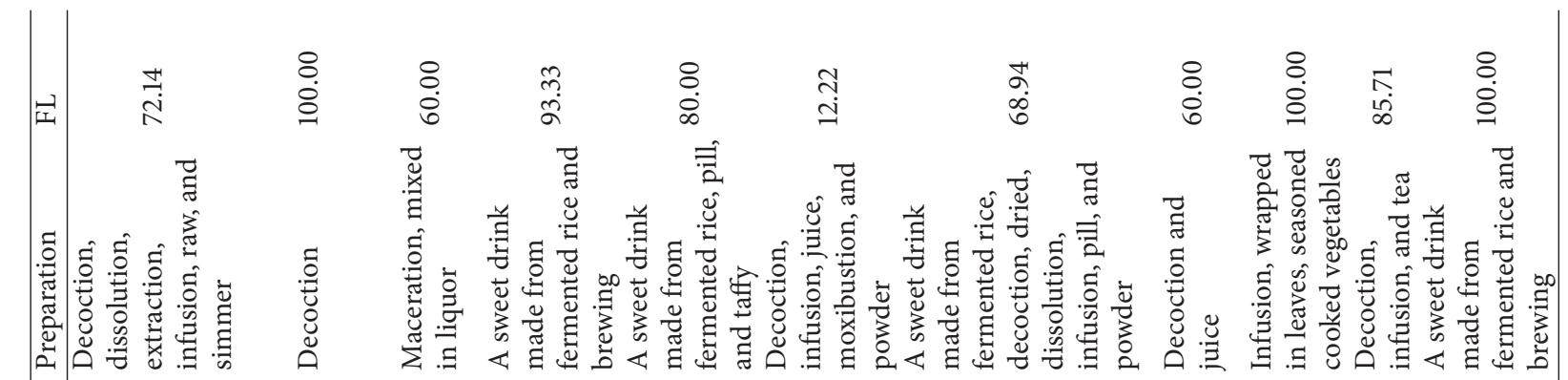

芯

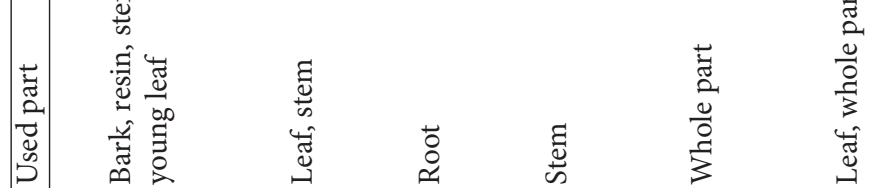

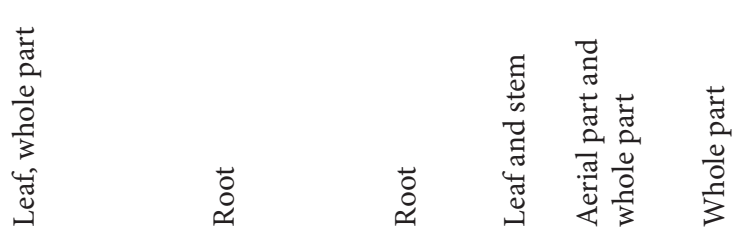

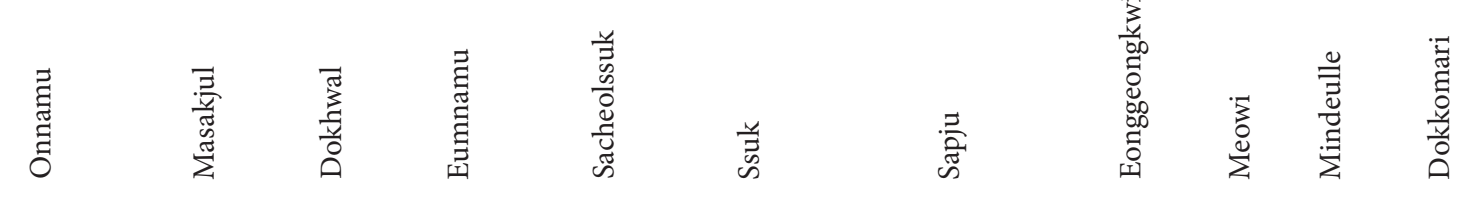

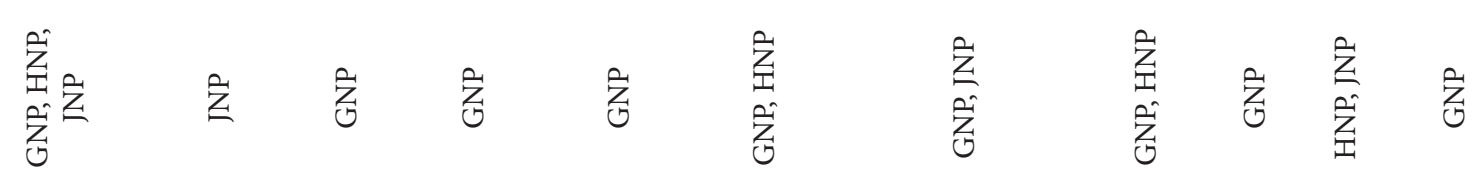

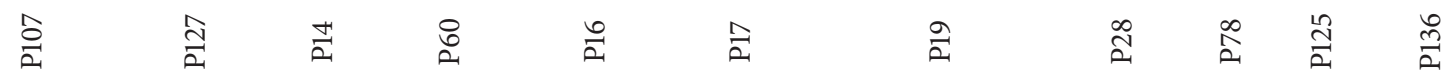
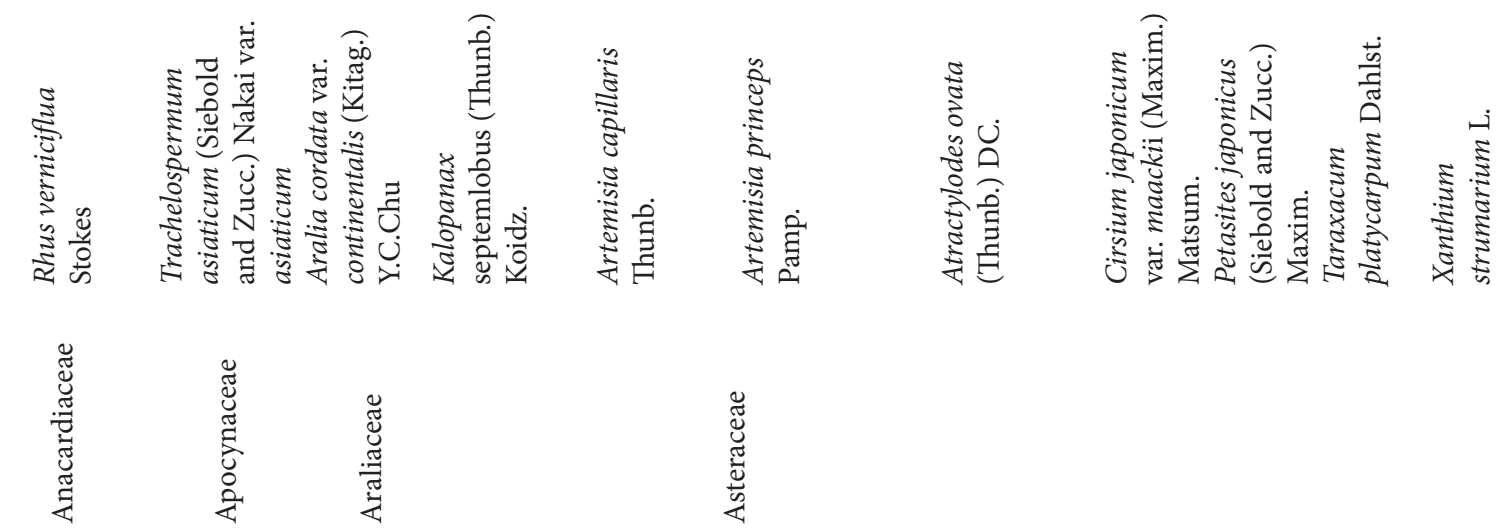

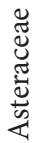




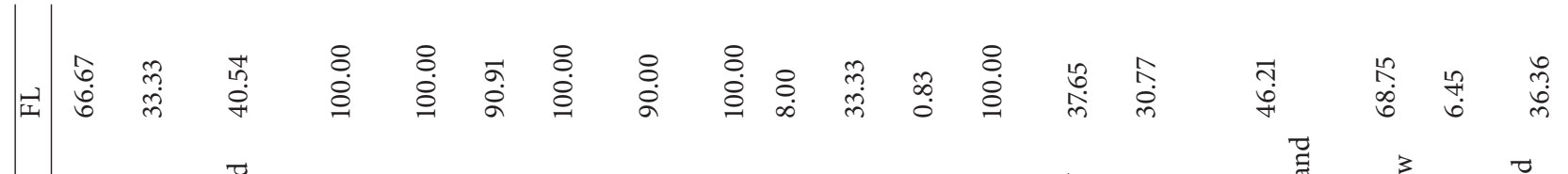

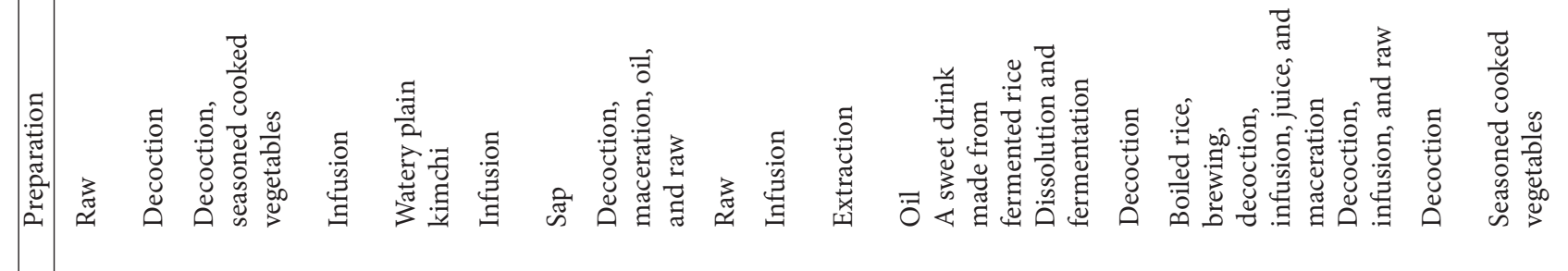

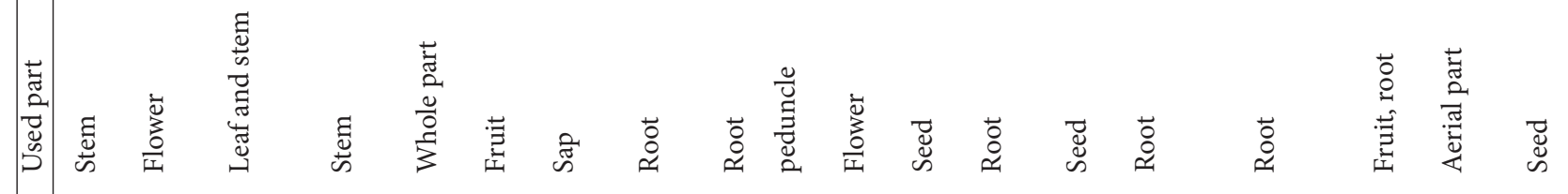

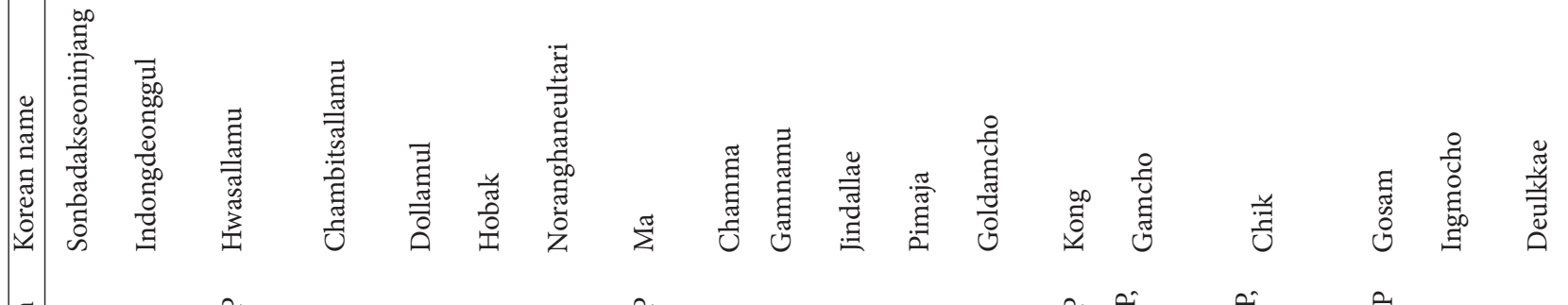

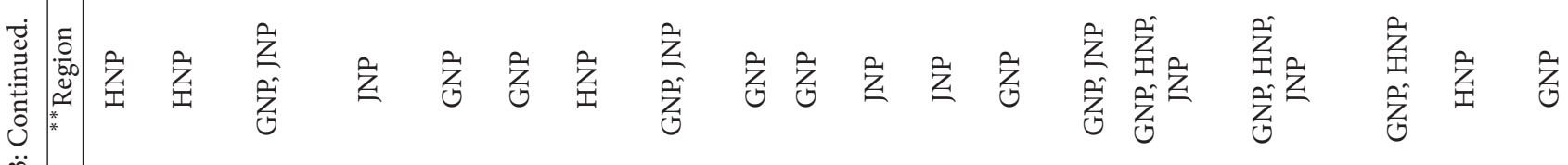

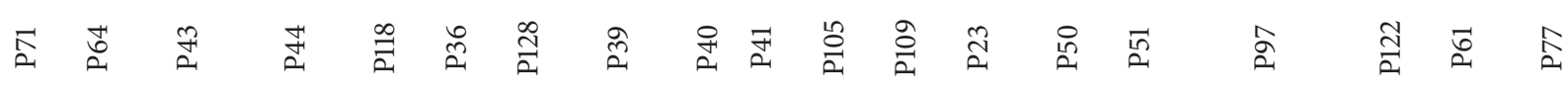

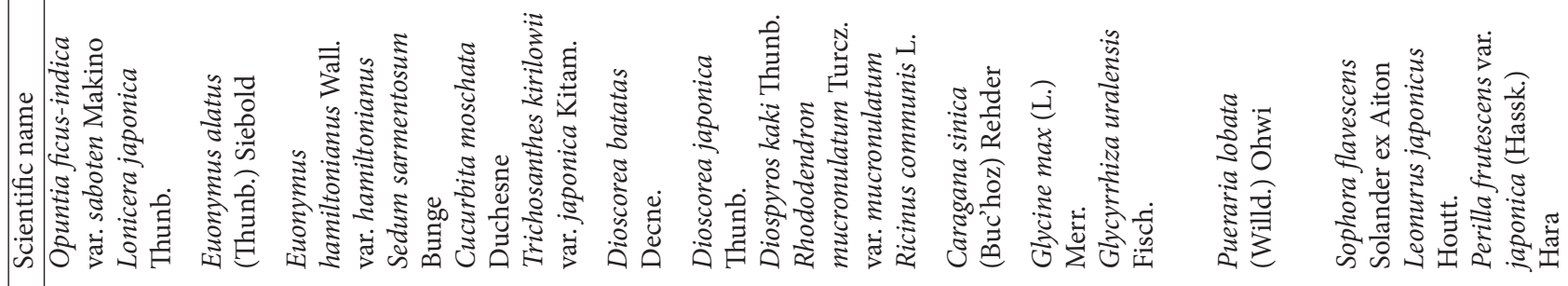

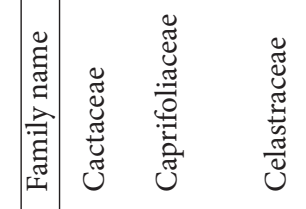

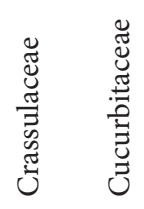

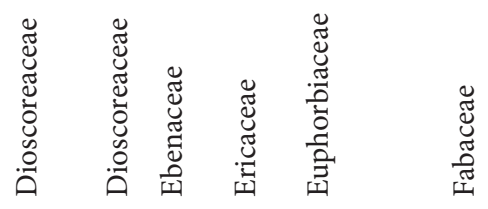




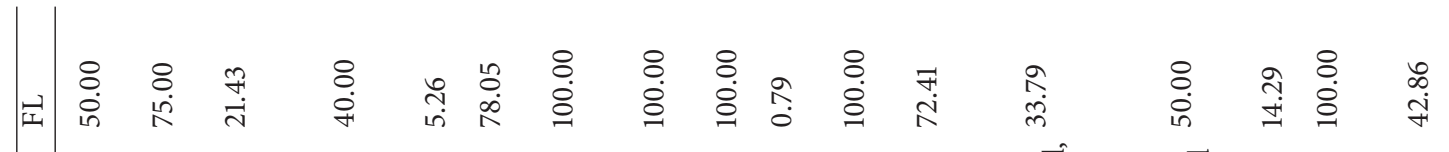

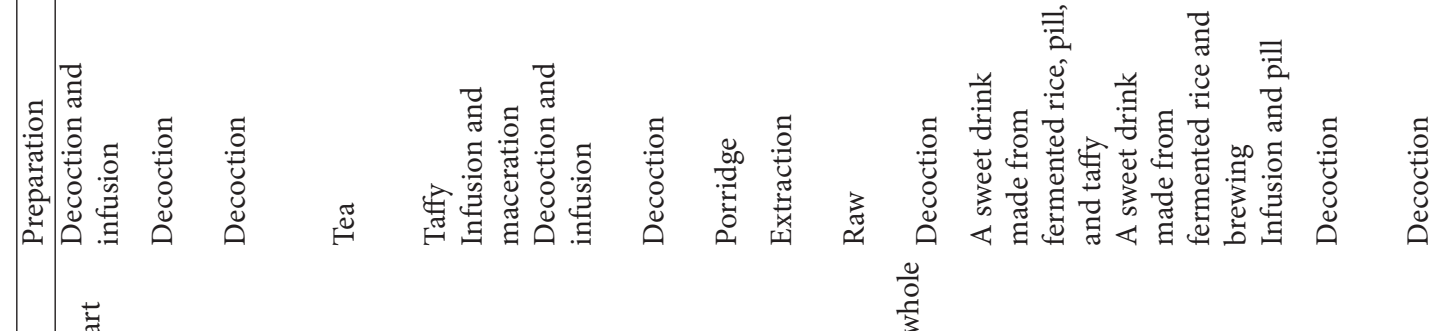

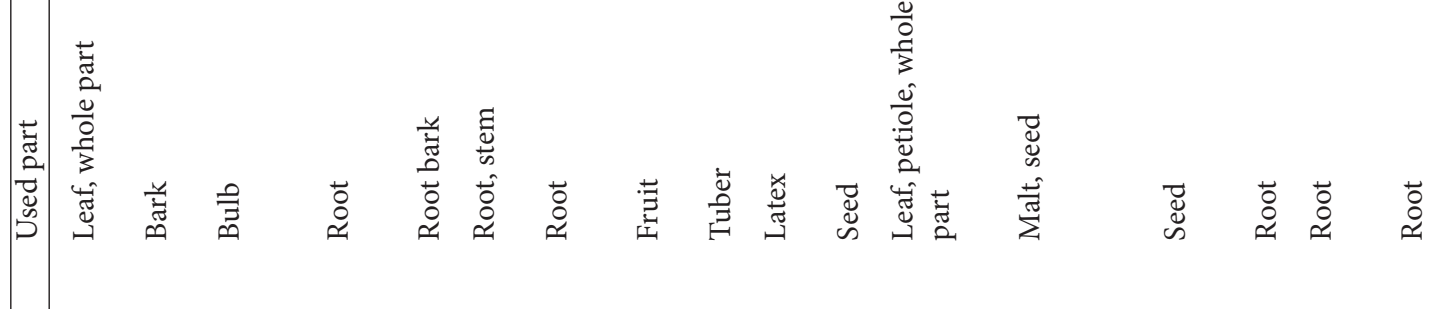

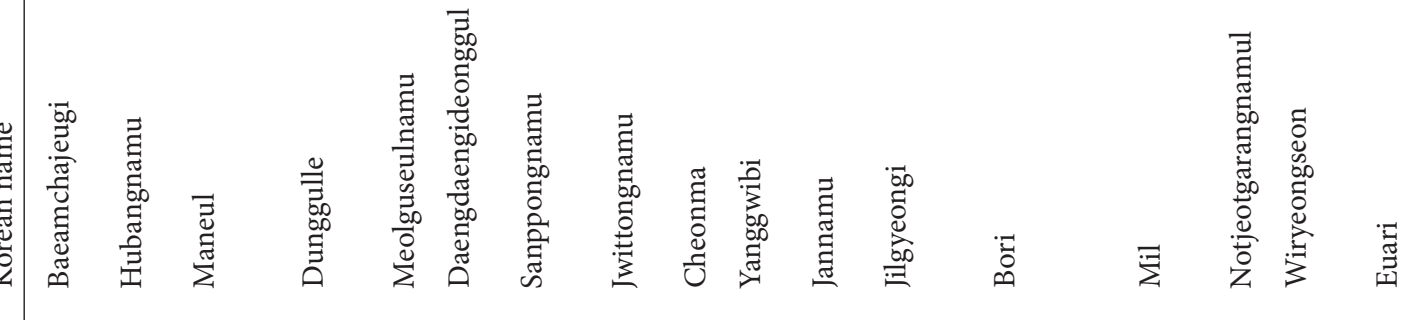

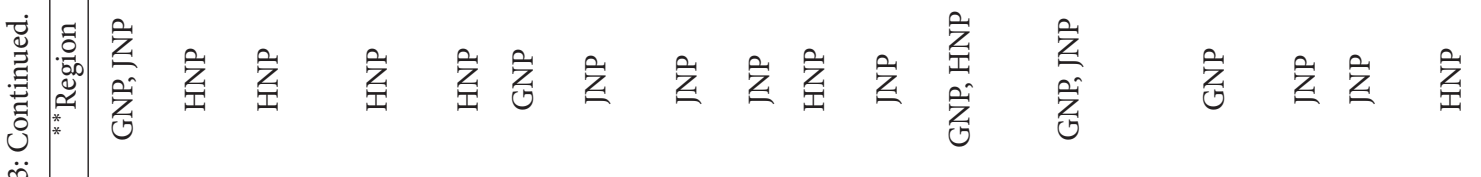

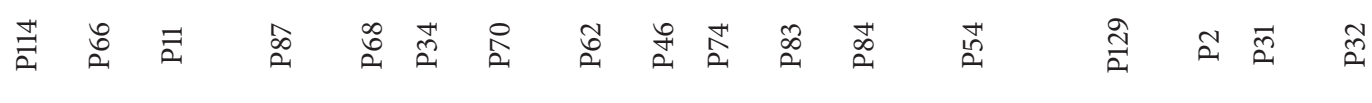

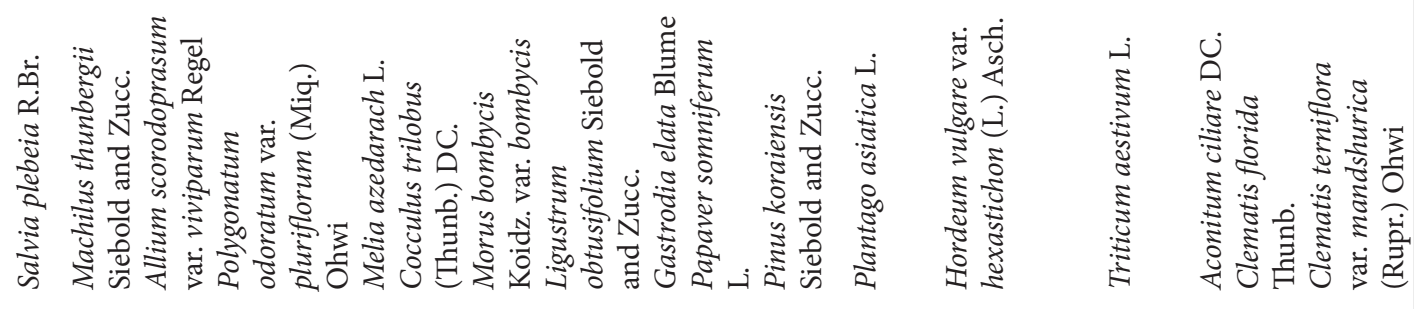

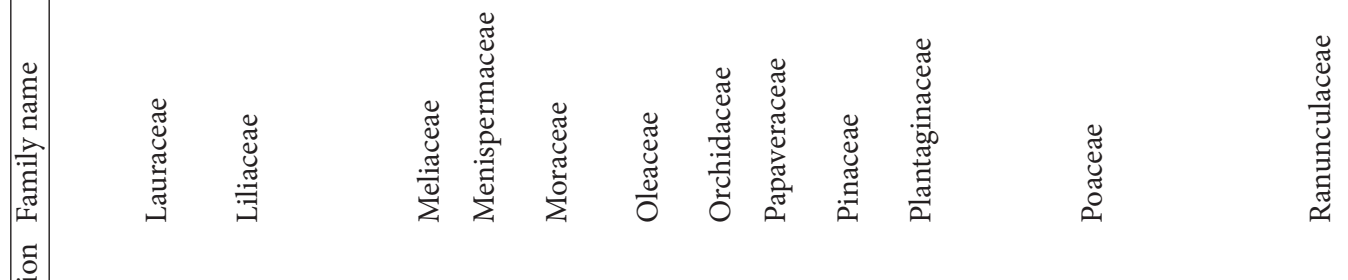




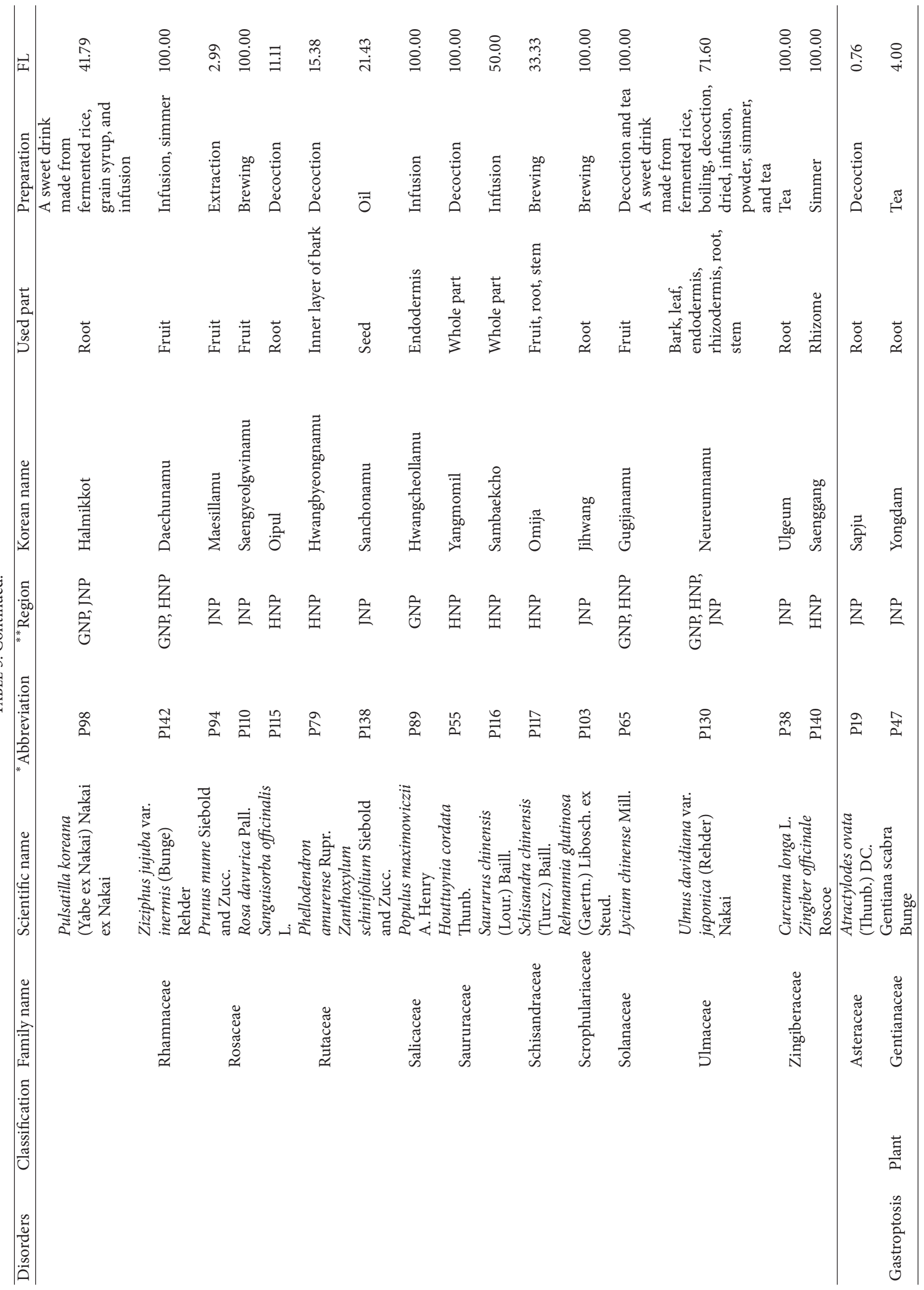




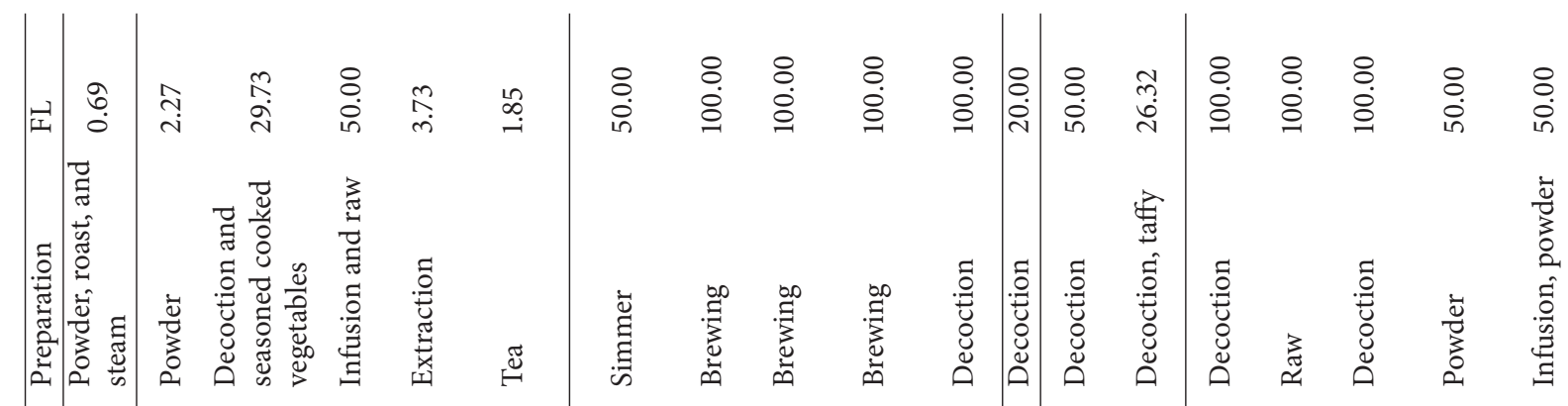

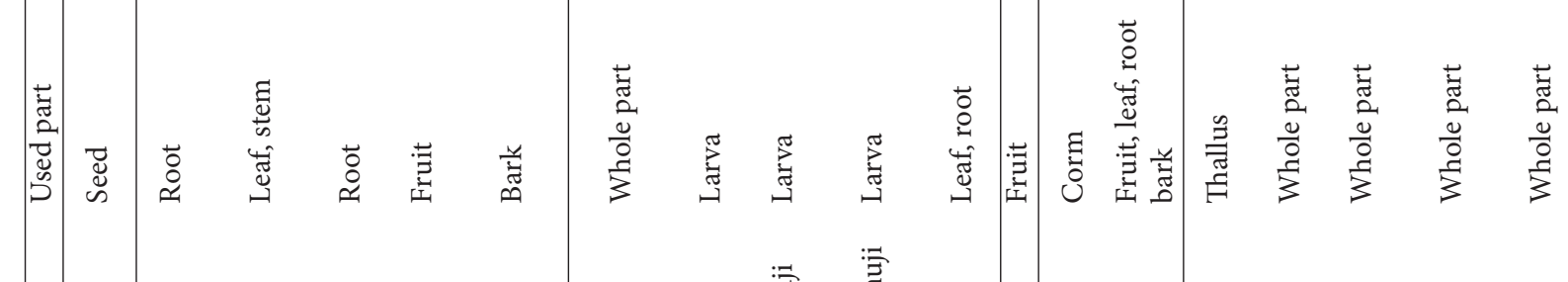
| In

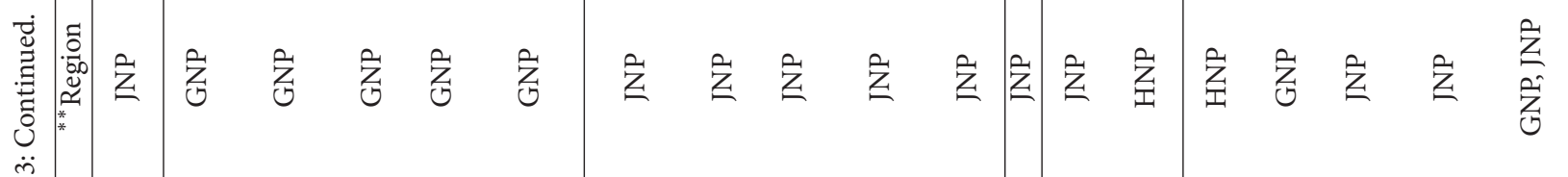
寊 荬

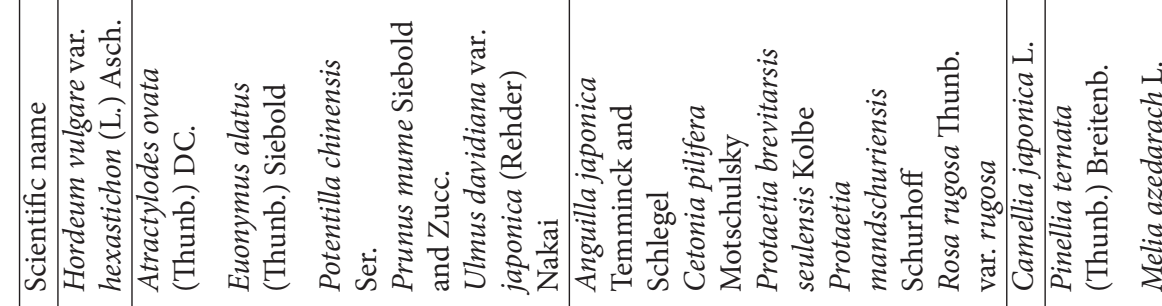

壳 


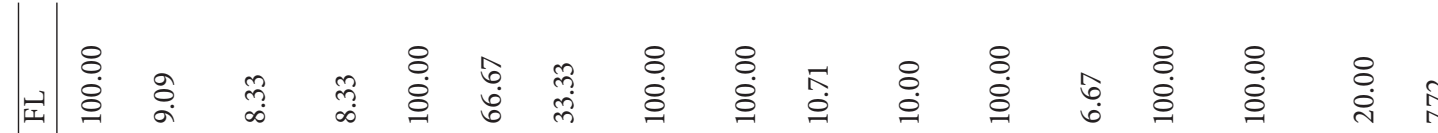

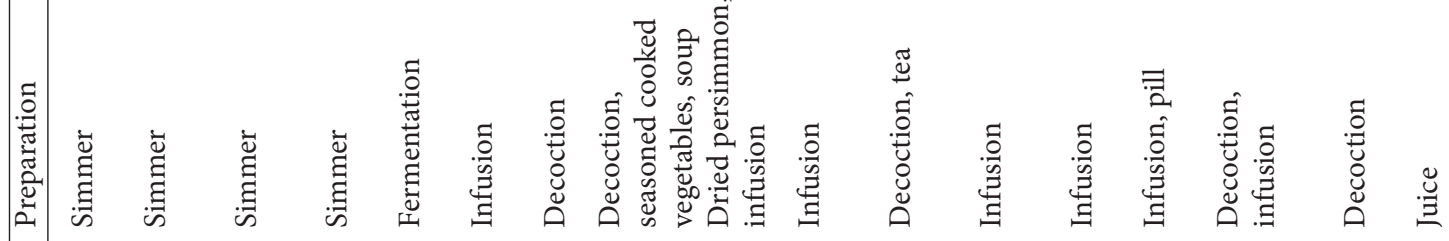

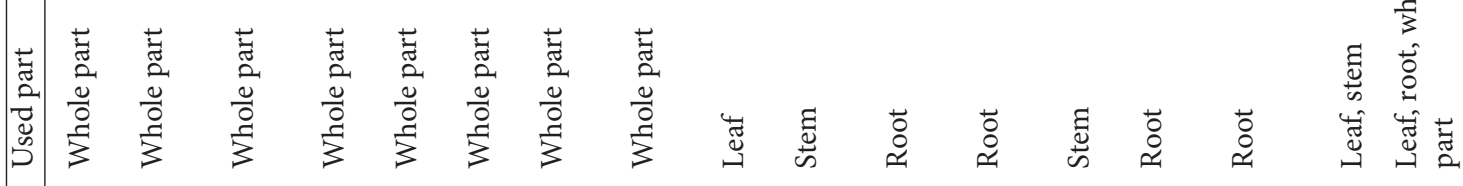

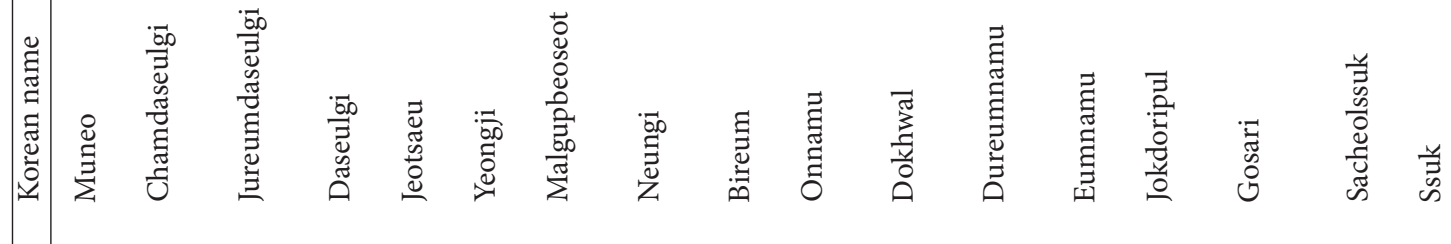

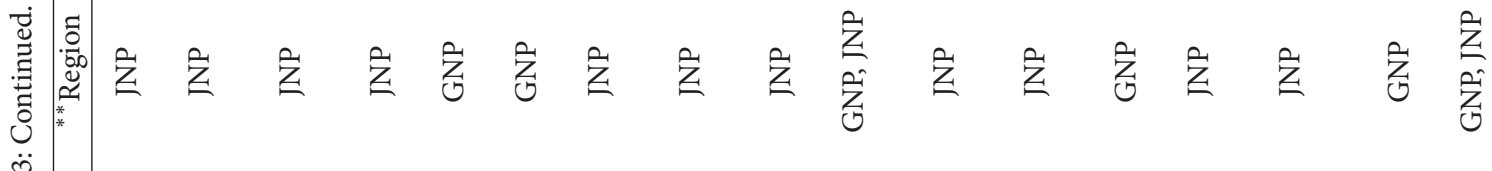

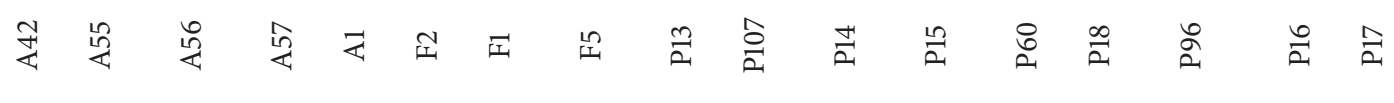

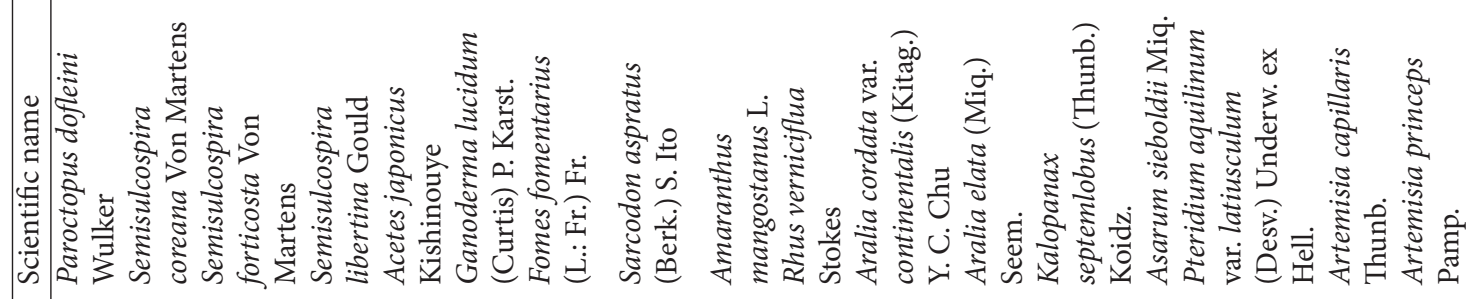

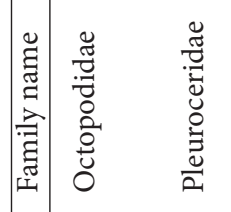

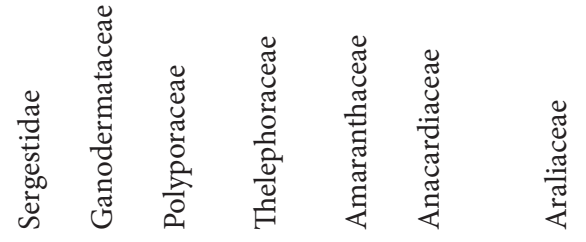

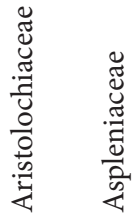

空 


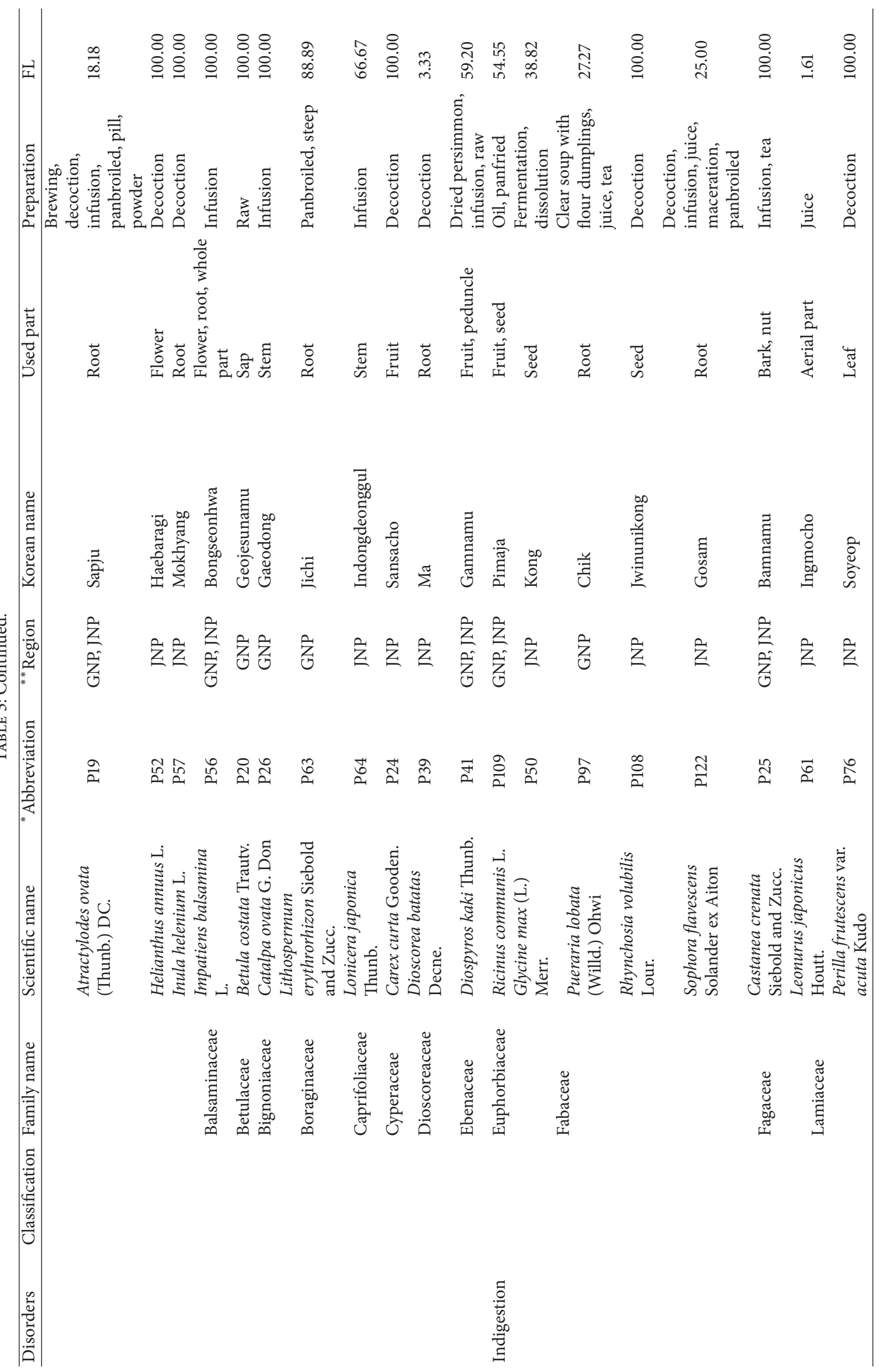




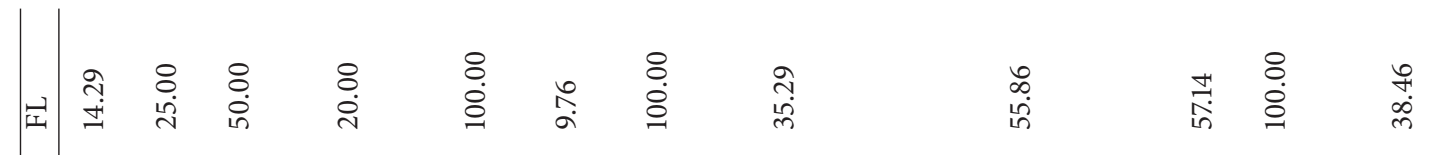

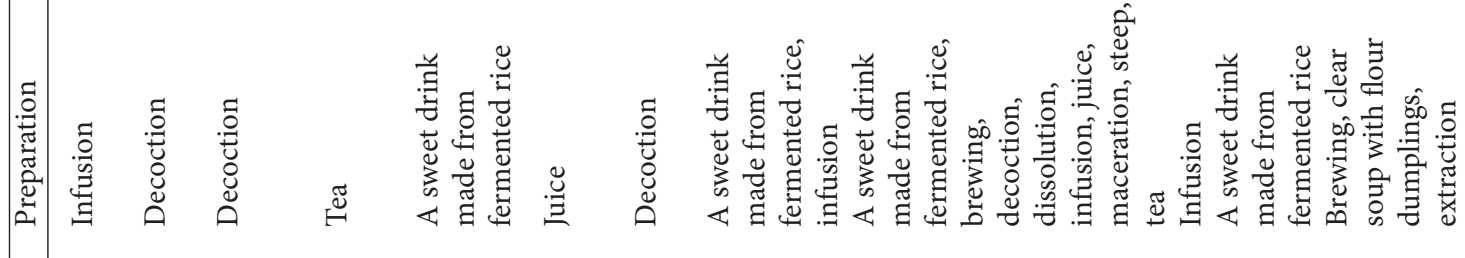

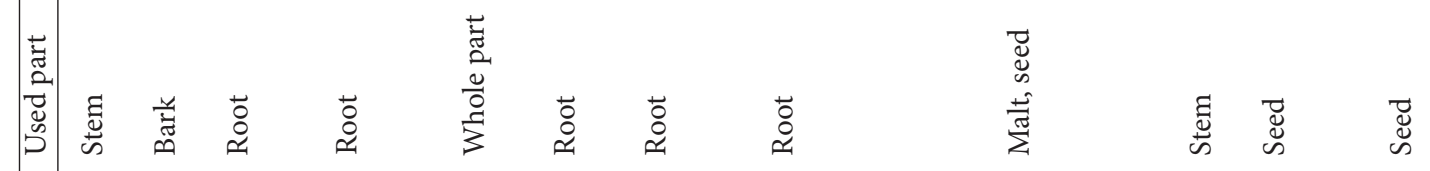

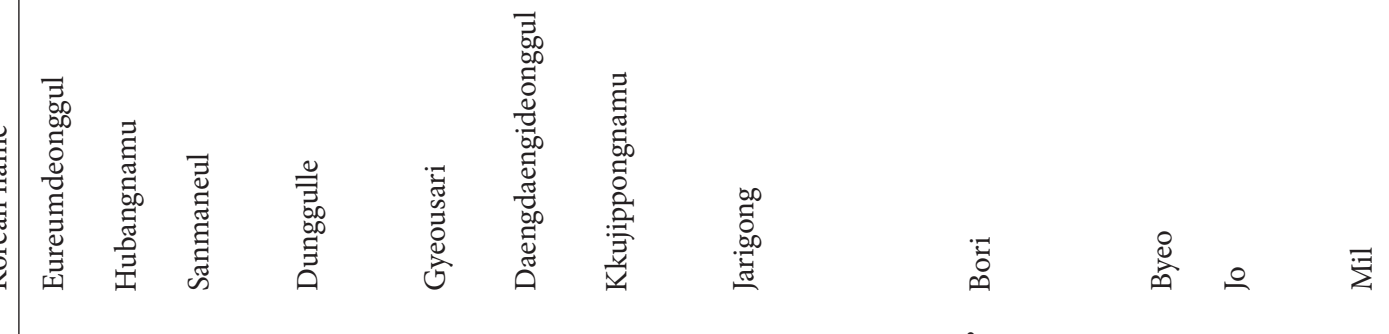

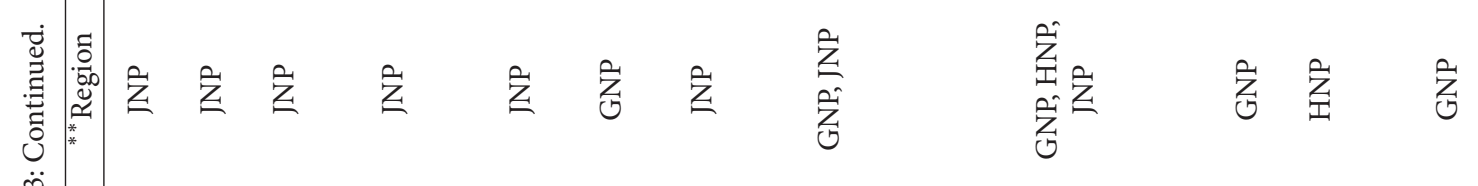

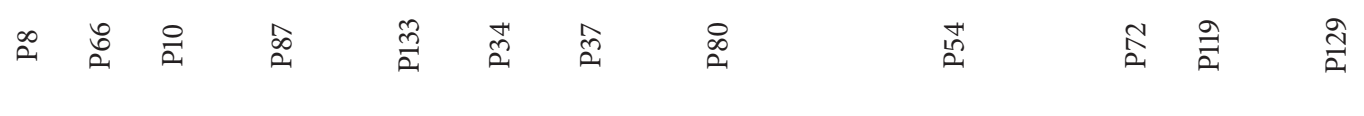

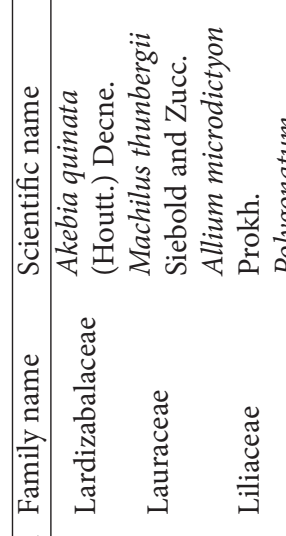

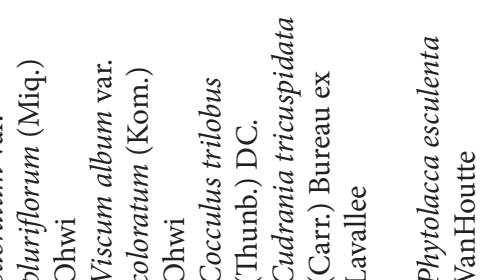

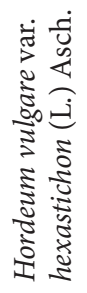

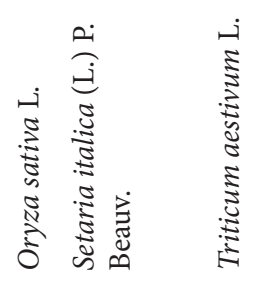

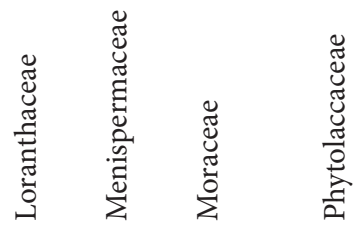

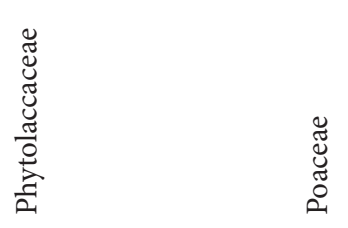




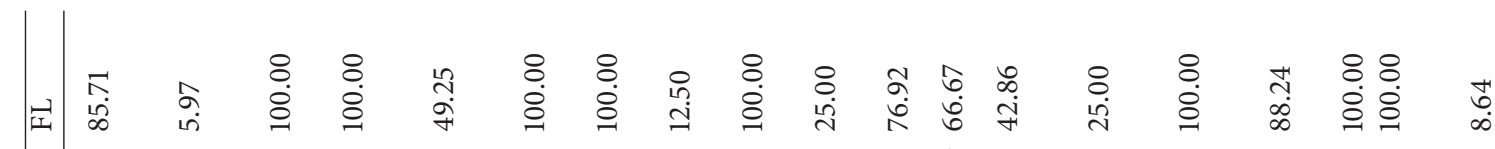

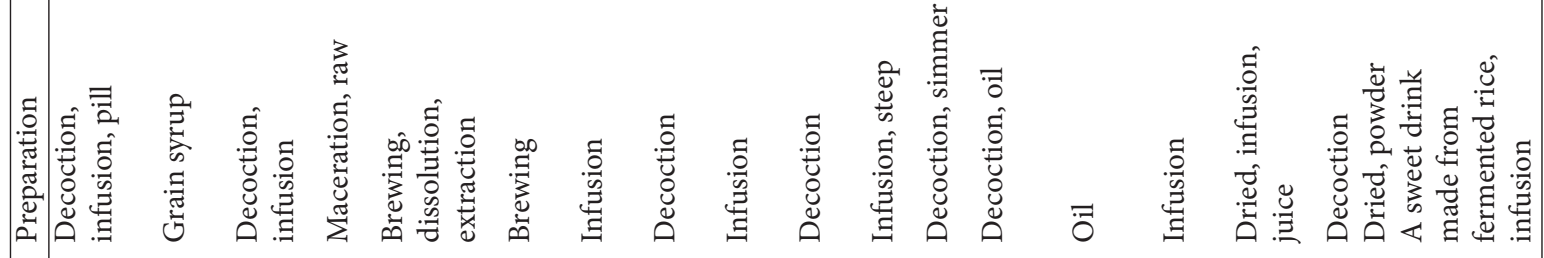

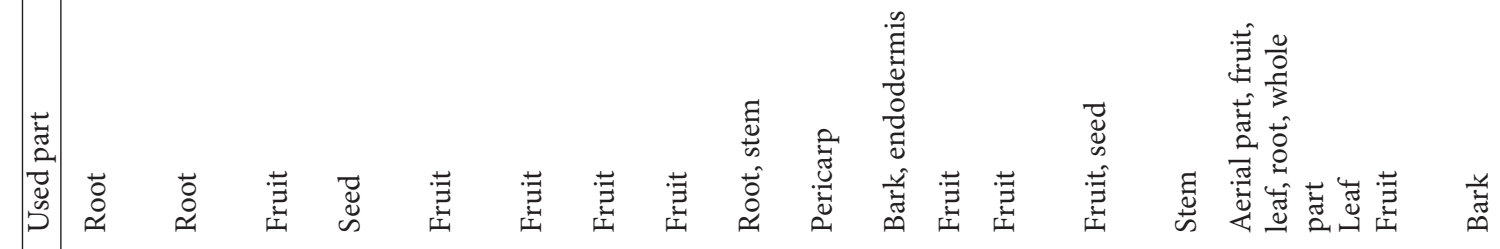

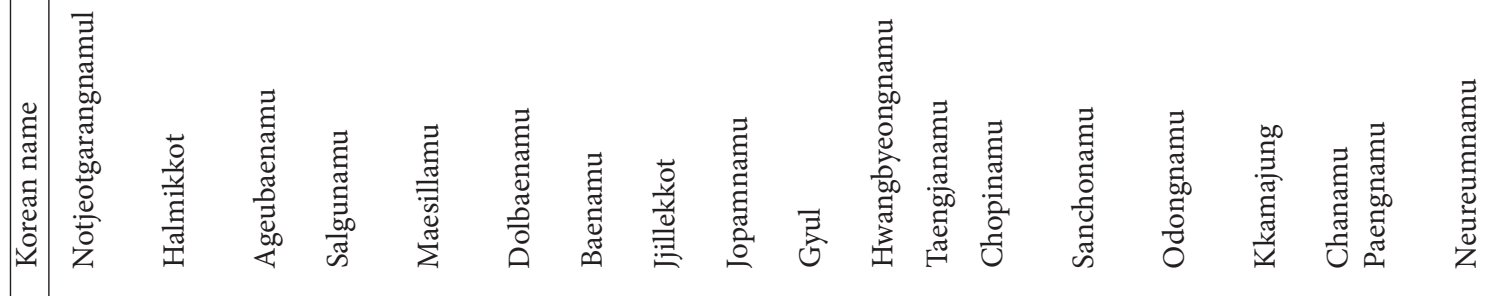

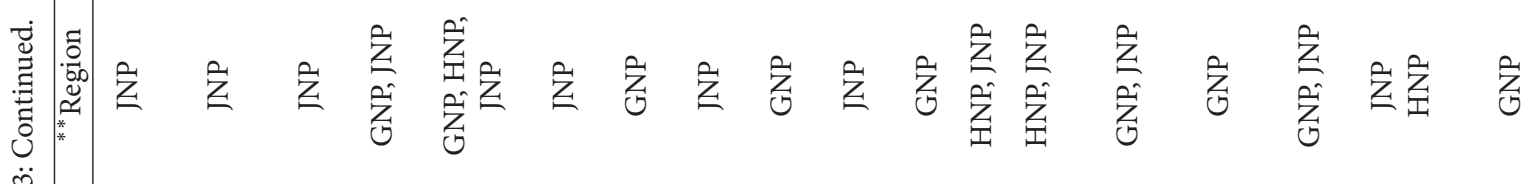

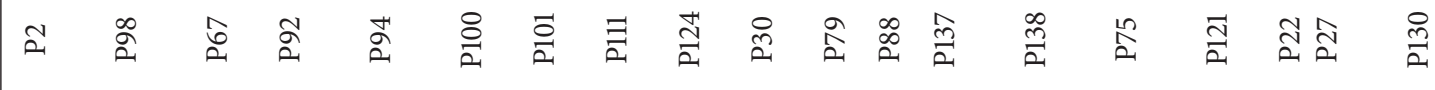

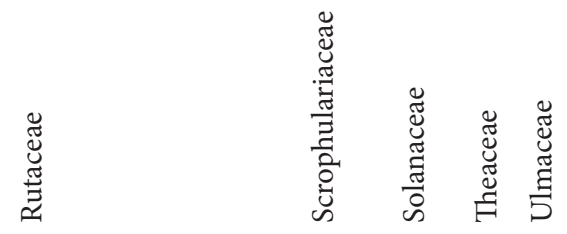




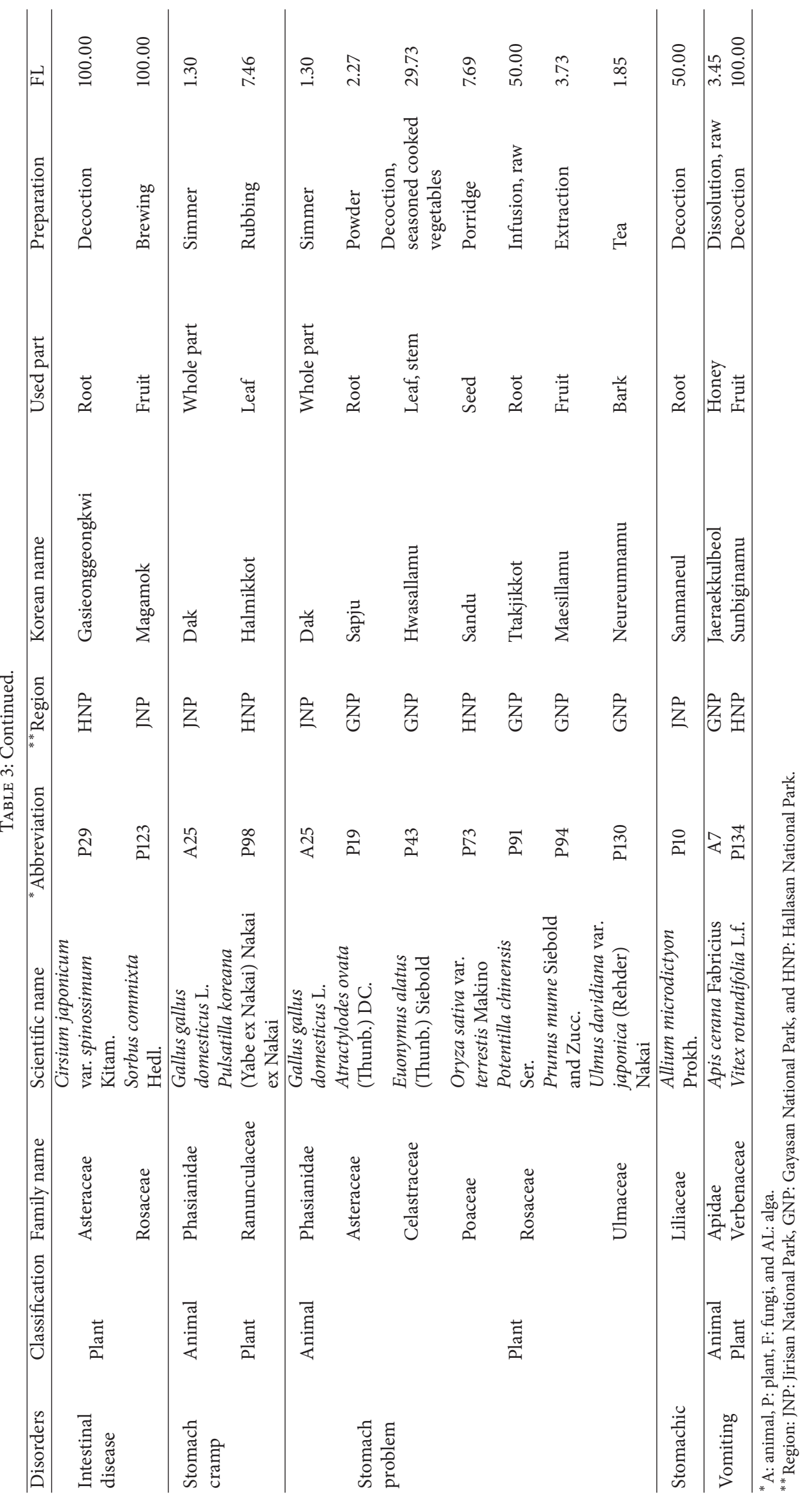


TABLE 4: Analytic results of ethnomedicinal practices recorded in the three national parks.

\begin{tabular}{lcccc}
\hline Results & JNP & GNP & HNP & Total \\
\hline $\begin{array}{l}\text { Species } \\
\text { Therapies }\end{array}$ & 166 & 76 & 58 & 220 \\
$\begin{array}{l}\text { (kinds) } \\
\text { Used parts }\end{array}$ & 272 & 176 & 92 & 490 \\
$\begin{array}{l}\text { Preparations } \\
\text { (modes) }\end{array}$ & 28 & 21 & 20 & 43 \\
$\begin{array}{l}\text { Disorders } \\
\text { types) }\end{array}$ & 20 & 11 & 21 & 42 \\
\hline
\end{tabular}

indicate a higher rate of informant consensus among the category of disorders.

The category with the highest degree of consensus from the informants were enteritis and gastralgia (1.0), followed by indigestion (0.94), constipation (0.93), abdominal pain and gastroenteric trouble (0.92), and gastric ulcers (0.91). The lowest degree of consensus was for gastroptosis, enterotoxin, hema feces, and other disorders (Table 6). These results denote that ethnomedicinal practices have been applied more often to minor health issues related to gastrointestinal disorders.

Generally, people suffering from serious gastrointestinal disorders have been treated in the hospital using conventional medicine or Korean traditional medicine. However, ethnomedicinal practices have been used to cure minor disorders.

Comparative consideration to results of the ICF among the three national parks and the agreement of consensus (ICF value, 1.00) from the informants in HNP obtained eight disorders, which include dysentery, gastralgia, gastric cancer, gastritis, hookworm, stomach cramps, stomach problems, and vomiting, while JNP and GNP depicted only enteritis and constipation, respectively.

These results confirm that the people of HNP have nearly the same ethnomedicinal knowledge for the treatment of gastrointestinal disorders because the communities have been isolated from other communities for many years.

3.3.2. Fidelity Level (FL). The FL is useful for identifying the informants' most preferred species in use for treating certain gastrointestinal disorders. This information reveals that the informants had a tendency to rely on one specific species for treating one specific disorder rather than for several different disorders. The FL values in this study varied from $1.0 \%$ to $100 \%$.

Generally, a FL of $100 \%$ for a specific species indicates that all of the use-reports mentioned the same species for a specific treatment [41].

This study determined 71 species of plants with a FL of $100 \%$, even without considering species that were mentioned more than two times (Table 3). Among them, plants with a FL of $100 \%$ in JNP totaled 52 species, followed by 40 species in GNP, and 23 species in HNP.
Disorders containing a higher number of species assessed to a FL of $100 \%$ were gastroenteric trouble (19 species) and cases of indigestion (22 species).

Special attention was given to important species $(\mathrm{N}$, $\mathrm{Np}$ ) with a FL above $100 \%$, regarding the viewpoint of the number of times mentioned and the consensus level for the specific disorders, which include Spiraea prunifolia f. simpliciflora Nakai $(224,224)$, Impatiens balsamina L. as plants and Acetes japonicus Kishinouye $(17,17)$ as an animal cure for indigestion, Xanthium strumarium L. and Petasites japonicas (Siebold and Zucc.) Maxim. as plants used for curing gastroenteric trouble, Zinnia violacea Cav. and Platycarya strobilacea Siebold and Zucc. as plants used in treating abdominal pain, and Viola verecunda A. Gray as a plant used in treating dysentery (Table 3).

Through further study, these species possess a much higher potential in being used in the development of new functional supplements for treating specific gastrointestinal disorders.

\subsubsection{INA between Gastrointestinal Disorders and Medicinal} Species. INA has originally analyzed social phenomenon and trends through the internetwork of components [42]. Our research has attempted to analyze the interrelationship between gastrointestinal disorders and the medicinal species recorded in the communities.

Considering Figure 2 about the internetwork between disorders and the medicinal species within all communities of this study, all medicinal species are grouped in the center for indigestion, diarrhea, abdominal pain, and gastroenteric trouble (Figure 2(a)), respectively. This distribution pattern is similar to the results of JNP and GNP. However, in case of HNP, indigestion is separated from the main disorders groups. This difference caused that the communities of HNP have been separated from the land communities for a long period of time.

In regard to the INA distribution map for JNP, the locations for the disorders of hema feces, intestinal disease, and hematemesis were fairly distinct from the four main disorders groups. Also, the cure for enteritis, hookworm, intestinal disease, stomach cramp, and stomachic is applied for only one medicinal species (Figure 2(b)).

In the case of GNP, gastritis, gastric ulcers, heartburn, and stomach problems were located as a distinct group separated from the four main disorder groups. Because this group consisted of minor stomach ailments having similar inclination, Zanthoxylum piperitum (L.) DC., Potentilla chinensis Ser., Euonymus alatus (Thunb.) Siebold, Atractylodes ovate (Thunb.) DC., and Ulmus davidiana var. japonica (Rehder) Nakai worked as possible cures as they possessed a high possibility in containing the same components for treatment (Figure 2(c)).

Within HNP, indigestion, intestinal disease, vomiting, stomach cramps, and enterotoxin were individually distinct from the three main disorder groups. This distribution pattern suggests that the application width of medicinal species to treat each disorder is limited for treating each disorder relative to the other communities (Figure 2(d)). 


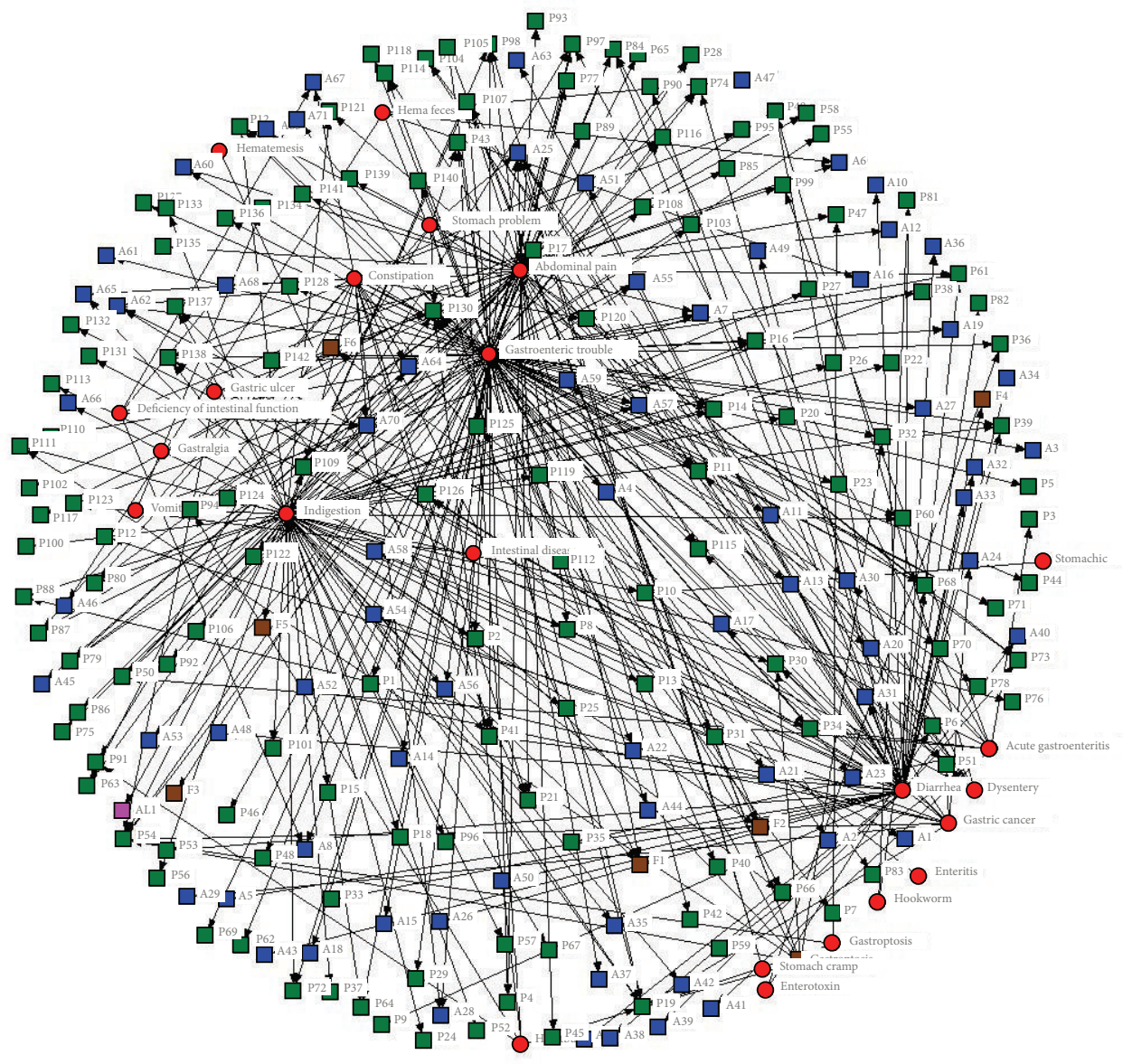

(a)

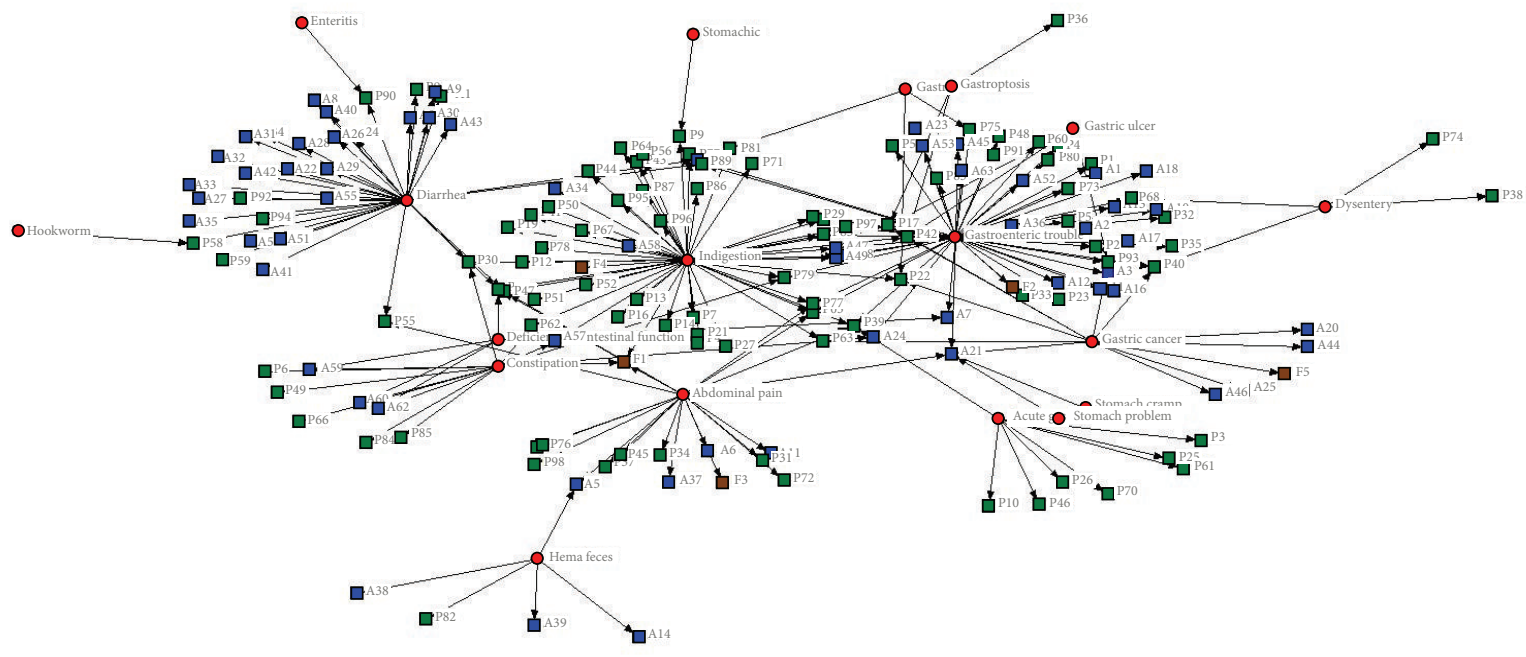

FIgure 2: Continued. 


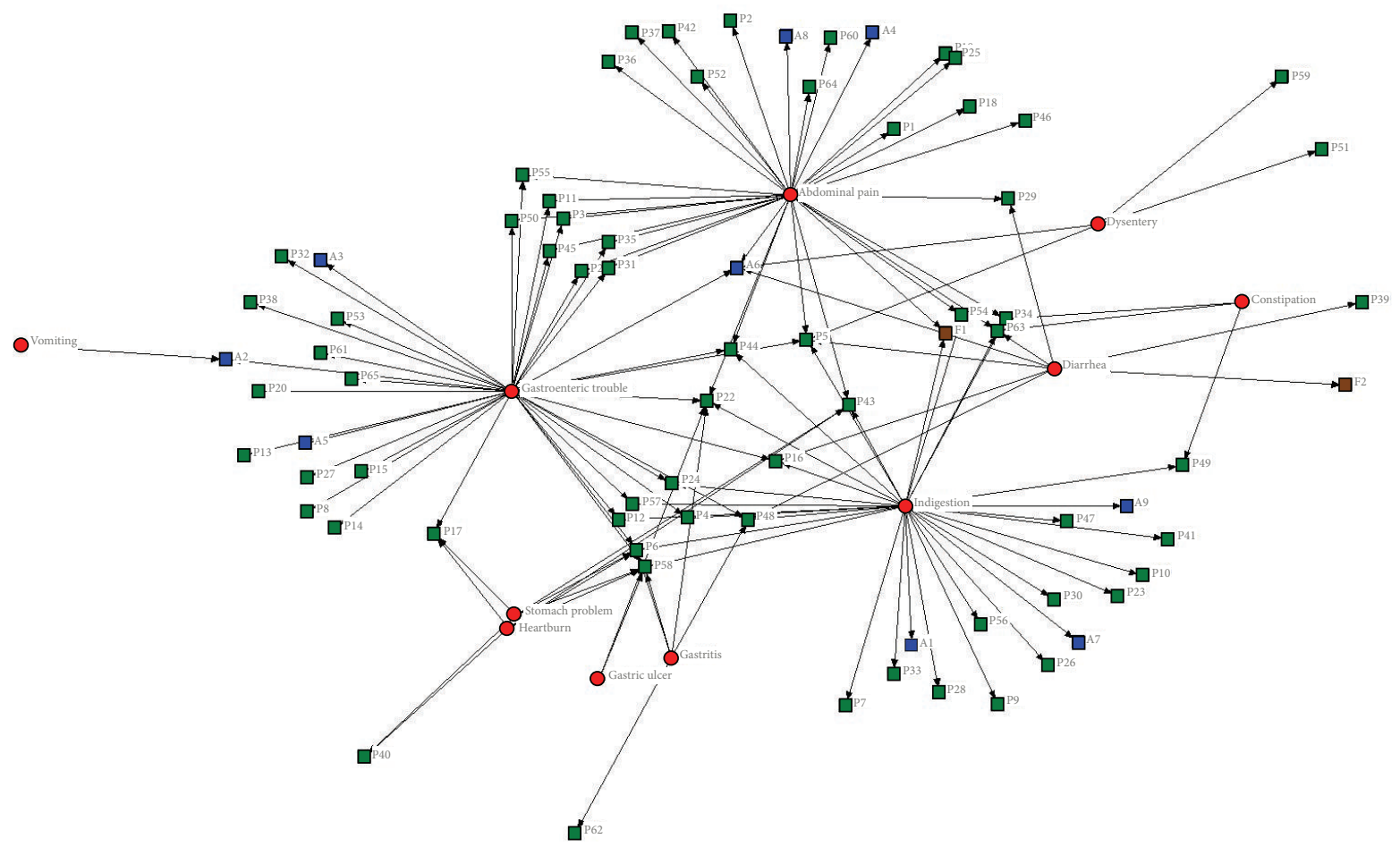

(c)

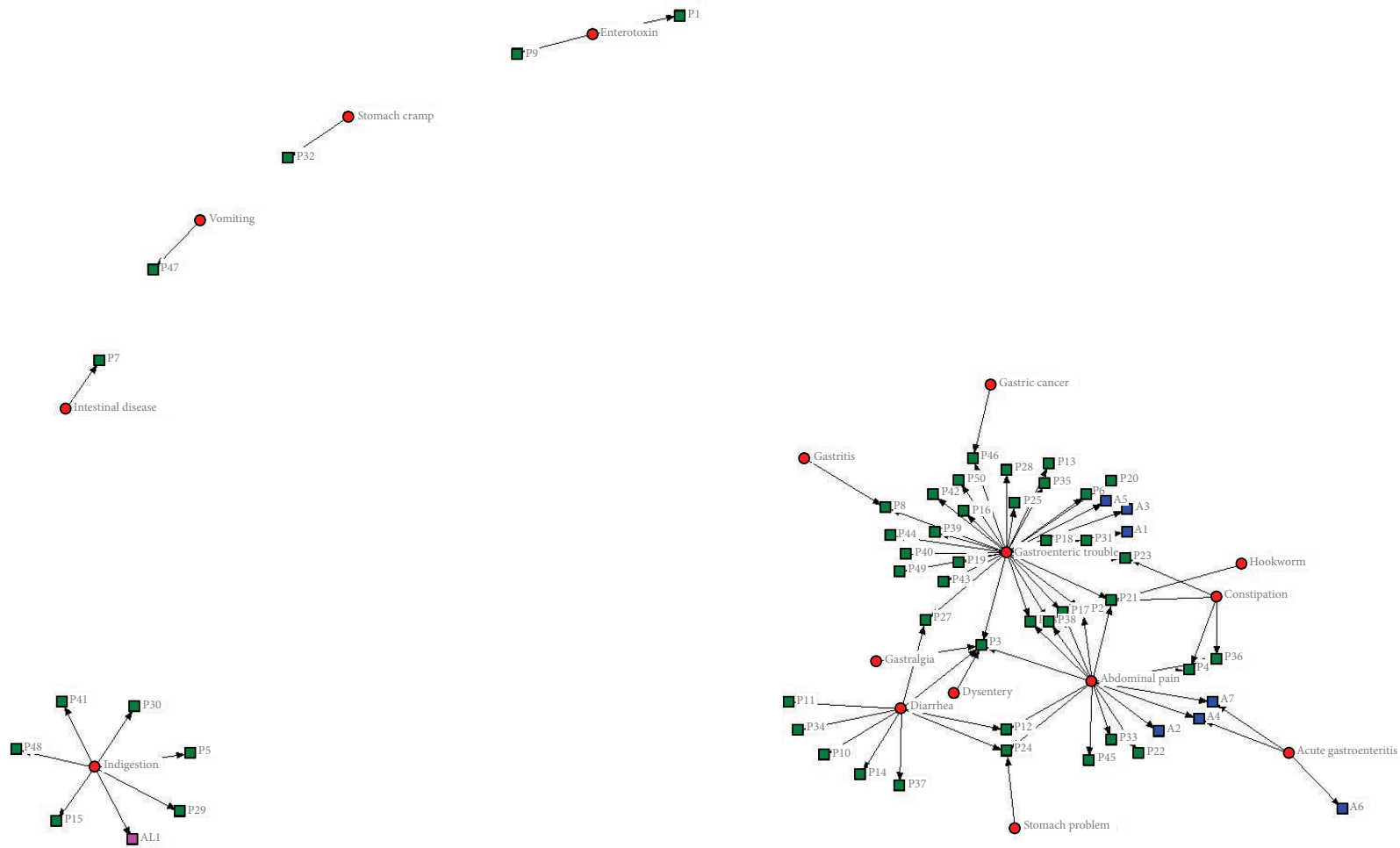

(d)

Figure 2: Internetwork analysis (INA) of three national parks ((a) total, (b) JNP, (c) GNP, and (d) HNP). *Abbreviation form of each is explained in Table 3: A (animal), P (plant), F (fungi), AL (algae), $\square$ (species), and $\bigcirc$ (disorders). 
TABLE 5: Number of times mentioned by informants and medicinal species for treating each disorder.

\begin{tabular}{|c|c|c|c|c|}
\hline Diseases & $\begin{array}{c}\text { JNP } \\
\text { Number of times } \\
\text { mentioned } \\
\text { (species) }\end{array}$ & $\begin{array}{c}\text { GNP } \\
\text { Number of times } \\
\text { mentioned } \\
\text { (species) }\end{array}$ & $\begin{array}{c}\text { HNP } \\
\text { Number of times } \\
\text { mentioned } \\
\text { (species) }\end{array}$ & $\begin{array}{c}\text { Total } \\
\text { Number of times } \\
\text { mentioned } \\
\text { (species) }\end{array}$ \\
\hline Abdominal pain & $161(21)$ & $516(32)$ & $82(16)$ & $759(59)$ \\
\hline Acute gastroenteritis & $41(8)$ & & $6(3)$ & 47 (11) \\
\hline Constipation & $115(15)$ & $142(3)$ & $36(4)$ & $293(20)$ \\
\hline $\begin{array}{l}\text { Deficiency of intestinal } \\
\text { function }\end{array}$ & $19(5)$ & & & $19(5)$ \\
\hline Diarrhea & $111(36)$ & $87(8)$ & $39(9)$ & $237(48)$ \\
\hline Dysentery & $6(4)$ & $42(4)$ & $3(1)$ & $51(8)$ \\
\hline Enteritis & $2(1)$ & & & $2(1)$ \\
\hline Enterotoxin & & & $2(2)$ & $2(2)$ \\
\hline Gastralgia & & & $5(1)$ & $5(1)$ \\
\hline Gastric cancer & $14(12)$ & & $3(1)$ & $17(12)$ \\
\hline Gastric ulcer & $3(3)$ & $20(2)$ & & $23(3)$ \\
\hline Gastritis & $12(3)$ & $20(5)$ & $4(1)$ & $36(9)$ \\
\hline Gastroenteric trouble & $238(54)$ & $755(35)$ & $118(30)$ & $1,111(94)$ \\
\hline Gastroptosis & $3(3)$ & & & $3(3)$ \\
\hline Heartburn & & $28(5)$ & & $28(5)$ \\
\hline Hema feces & $6(5)$ & & & $6(5)$ \\
\hline Hematemesis & $1(1)$ & & & $1(1)$ \\
\hline Hookworm & $1(1)$ & & $5(1)$ & $6(2)$ \\
\hline Indigestion & $302(52)$ & $829(31)$ & $21(7)$ & $1,152(72)$ \\
\hline Intestinal ailment & $2(1)$ & & $1(1)$ & $3(2)$ \\
\hline Stomach cramp & $1(1)$ & & $5(1)$ & $6(2)$ \\
\hline Stomach problem & $6(4)$ & $28(5)$ & $2(1)$ & $31(7)$ \\
\hline Stomachic & $1(1)$ & & & $1(1)$ \\
\hline Vomiting & $1(1)$ & $1(1)$ & $4(1)$ & $5(2)$ \\
\hline Total & $1,040(166)$ & $2,468(76)$ & $336(58)$ & $3,844(220)$ \\
\hline
\end{tabular}

\section{Conclusion}

This research is the first study in the world to analyze and compare the ethnomedicinal practices of communities for treating gastrointestinal disorders. As the research method of this study, comparative quantitative analysis will contribute to the availability of orally transmitted ethnomedicinal knowledge. Additionally, the results of this study are confirmed due to the results obtained through investigation by 507 informants within the 185 research sites.

From this research, the recording of 490 ethnomedicinal practices being applied to the use of 220 medicinal species to treat 24 gastrointestinal disorders was extremely valuable. Particularly, the present usage of various medicinal species displays evidence as to which ethnomedicinal practices are continuously transmitted within the communities. However, this present situation is not sustainable because the communities of these study areas consist of an aging society. It has become necessary for appropriate measures to be taken to conserve these ethnomedicinal practices.
Our research suggests that treatment for gastroenteric trouble and indigestion among the gastrointestinal disorders uses ethnomedicinal practices more than any other type of treatment, as the communities used $75.5 \%$ of all medicinal species for treating these two diseases, $63.3 \%$ of the total number of all ethnomedicinal practices, and mentioned by $58.9 \%$ of all informants. Also, these two disorders contained the highest numbers of medicinal species within a FL of $100 \%$. Through further study, the ethnomedicinal practices for these conditions possess a much higher potential in being used in the development of new practices.

According to the number of medicinal species applied to ethnomedicinal practices and the number of disorders treated by these ethnomedicinal practices, the numbers of JNP were much higher than the other two national parks. It is inferred that the region of JNP was the original center of Korean traditional medicine.

On the other hand, the communities of HNP depict a higher degree of agreement in the consensus to ethnomedicinal practices. This data explains that the communities of 
TABLE 6: Informant consensus factor (ICF) of the communities of three national parks.

\begin{tabular}{|c|c|c|c|c|}
\hline Disorders & JNP & GNP & HNP & Total \\
\hline Abdominal pain & 0.88 & 0.94 & 0.81 & 0.92 \\
\hline Acute gastroenteritis & 0.83 & - & 0.60 & 0.78 \\
\hline Constipation & 0.88 & 0.99 & 0.91 & 0.93 \\
\hline $\begin{array}{l}\text { Deficiency of intestinal } \\
\text { function }\end{array}$ & 0.78 & - & - & 0.78 \\
\hline Diarrhea & 0.68 & 0.92 & 0.79 & 0.80 \\
\hline Dysentery & 0.40 & 0.93 & 1.00 & 0.86 \\
\hline Enteritis & 1.00 & - & - & 1.00 \\
\hline Enterotoxin & - & - & + & + \\
\hline Gastralgia & - & - & 1.00 & 1.00 \\
\hline Gastric cancer & + & 0.95 & 1.00 & + \\
\hline Gastric ulcer & + & - & - & 0.91 \\
\hline Gastritis & 0.82 & 0.79 & 1.00 & 0.77 \\
\hline Gastroenteric trouble & 0.78 & 0.95 & 0.75 & 0.92 \\
\hline Gastroptosis & + & - & - & + \\
\hline Heartburn & - & 0.85 & - & 0.85 \\
\hline Hema feces & + & - & - & + \\
\hline Hematemesis & + & - & - & + \\
\hline Hookworm & + & - & 1.00 & 0.80 \\
\hline Indigestion & 0.83 & 0.96 & 0.70 & 0.94 \\
\hline Intestinal ailment & 1.00 & - & + & 0.50 \\
\hline Stomach cramp & + & - & 1.00 & 0.80 \\
\hline Stomach problem & 0.40 & 0.85 & 1.00 & 0.80 \\
\hline Stomachic & + & - & - & + \\
\hline Vomiting & - & + & 1.00 & 0.75 \\
\hline
\end{tabular}

-: Ailments were not mentioned in each national park.

+ : Below 0.40 .

HNP, as island people, were limited in their movement to other regions and strictly collected large amounts of independent ethnomedicinal knowledge, only sharing within their own communities, which was distinct from the inland communities.

These trends were confirmed by the results of the INA as the internetwork maps of JNP and GNP were similar, while the map of HNP was moderately different. These results are reflected by the three-dimensional patterns of the ethnomedicinal knowledge held within the communities of each national park.

More specifically, the use of INA as a tool of quantitative analysis in this study provides valuable internetwork maps between gastrointestinal disorders and medicinal species.

These maps are important data to understand the specific interrelationships between disease and ethnomedicinal practices in the intra- and intercommunities.

The authors believe that INA is a useful new tool for providing various interpretations to ethnomedicinal knowledge in the intra- and intercommunities. This study provides confidence in that the useful value of INA will extend beyond the existing understanding of ethnomedicinal knowledge for the future research of ethnomedicinal knowledge.

\section{Conflict of Interests}

The authors declare that there is no conflict of interests regarding the publication of this paper.

\section{Acknowledgments}

The authors are very grateful to all informants of the study area for sharing their oral traditional knowledge during the fieldwork surveys.

\section{References}

[1] T. Bubela and E. R. Gold, Genetic Resources and Traditional Knowledge, Edward Elgar, Northampton, Mass, USA, 2012.

[2] P. M. Unikrishnan and M. S. Suneetha, Biodiversity, Traditional Knowledge and Community Health: Strengthening Linkages, Xpress Pte, Singapore, 2012.

[3] J. Sharma, S. Gairola, R. D. Gaur, and R. M. Painuli, "The treatment of jaundice with medicinal plants in indigenous communities of the Sub-Himalayan region of Uttarakhand, India," Journal of Ethnopharmacology, vol. 143, no. 1, pp. 262291, 2012. 
[4] S. Shyamal, P. G. Latha, V. J. Shine, S. R. Suja, S. Rajasekharan, and T. Ganga Devi, "Hepatoprotective effects of Pittosporum neelgherrense Wight\&Arn., a popular Indian ethnomedicine," Journal of Ethnopharmacology, vol. 107, no. 1, pp. 151-155, 2006.

[5] B. A. Anderson, E. N. Anderson, T. Franklin, and A. D. de Cen, "Pathways of decision making among Yucatan Mayan traditional birth attendants," Journal of Midwifery and Women's Health, vol. 49, no. 4, pp. 312-319, 2004.

[6] S. E. Wilkinson and L. C. Callister, "Giving birth: the voices of Ghanaian women," Health Care for Women International, vol. 31, no. 3, pp. 201-220, 2010.

[7] F. M. Khameneh, "An ethnomedicine study among women in Uremia (North-West Iran)," Collegium Antropologicum, vol. 36, no. 2, pp. 491-497, 2012.

[8] F. U. Afifi-Yazar, V. Kasabri, and R. Abu-Dahab, "Medicinal plants from jordan in the treatment of diabetes: traditional uses vs in vitro and in vivo evaluations-part 2," Planta Medica, vol. 77, no. 11, pp. 1210-1220, 2011.

[9] H. Fabrega Jr., "An ethnomedical perspective of AngloAmerican psychiatry," The American Journal of Psychiatry, vol. 146, no. 5, pp. 588-596, 1989.

[10] M. Inhorn Millar and S. D. Lane, "Ethno-ophthalmology in the Egyptian delta: an historical systems approach to ethnomedicine in the Middle East," Social Science and Medicine, vol. 26, no. 6, pp. 651-657, 1988.

[11] C. Lans, "Comparison of plants used for skin and stomach problems in Trinidad and Tobago with Asian ethnomedicine," Journal of Ethnobiology and Ethnomedicine, vol. 3, article 3, 12 pages, 2007.

[12] K. A. Jernigan, "Barking up the same tree: a comparison of ethnomedicine and canine ethnoveterinary medicine among the Aguaruna," Journal of Ethnobiology and Ethnomedicine, vol. 5, article 33, 2009.

[13] G. J. Martínez and M. C. Luján, "Medicinal plants used for traditional veterinary in the Sierras de Córdoba (Argentina): an ethnobotanical comparison with human medicinal uses," Journal of Ethnobiology and Ethnomedicine, vol. 7, no. 1, article 23, 2011.

[14] H. Kim and M. Song, "Traditional plant-based therapies for respiratory diseases found in North Jeolla Province, Korea," Journal of Alternative and Complementary Medicine, vol. 18, no. 3, pp. 287-293, 2012.

[15] H. Kim and M. Song, "Oral traditional knowledge for the treatment of digestive system diseases investigated in north jeolla province, Korea," Journal of Medicinal Plant Research, vol. 5, no. 24, pp. 5730-5740, 2011.

[16] H. Kim and M.-J. Song, "Oral traditional plant-based therapeutic applications for pain relief recorded in North Jeolla province, Korea," Indian Journal of Traditional Knowledge, vol. 12, no. 4, pp. 573-584, 2013.

[17] M. Heinrich, A. Ankli, B. Frei, C. Weimann, and O. Sticher, "Medicinal plants in Mexico: healers' consensus and cultural importance," Social Science and Medicine, vol. 47, no. 11, pp. 1859-1871, 1998.

[18] M. Heinrich, S. Edwards, D. E. Moerman, and M. Leonti, "Ethnopharmacological field studies: a critical assessment of their conceptual basis and methods," Journal of Ethnopharmacology, vol. 124, no. 1, pp. 1-17, 2009.

[19] M. N. Alexiades, Selected guidelines for ethnobotanical researcha Field Manual, vol. 10 of Advances in Economic Botany, The New York Botanical Garden, Bronx, NY, USA, 1996.
[20] H. Kim and M.-J. Song, Ethnobotany, World Science, Seoul, Republic of Korea, 2008.

[21] H. Kim and M. Song, "Analysis and recordings of orally transmitted knowledge about medicinal plants in the southern mountainous region of Korea," Journal of Ethnopharmacology, vol. 134, no. 3, pp. 676-696, 2011.

[22] M. Song, H. Kim, B. Heldenbrand, J. Jeon, and S. Lee, "Ethnopharmacological survey of medicinal plants in Jeju Island, Korea," Journal of Ethnobiology and Ethnomedicine, vol. 9, no. 1, article 48, 12 pages, 2013.

[23] H. Kim and M. Song, "Ethnozoological study of medicinal animals on Jeju Island, Korea," Journal of Ethnopharmacology, vol. 146, no. 1, pp. 75-82, 2013.

[24] Ministry of Security and Public Administration, 2013, http:// www.mospa.go.kr.

[25] "Korea Meteorological Administration," 2013, http://www.kma. go.kr.

[26] H. Kim and M.-J. Song, Benefit-Sharing and Industrialization for Traditional Knowledge of Biological Genetic Resources: Prevention of Nagoya Protocol, World science, Seoul, Republic of Korea, 2011.

[27] G. J. Martin, Ethnobotany: A Methods Manual, Champman \& Hall, London, UK, 1995.

[28] M. Song and H. Kim, "Ethnomedicinal application of plants in the western plain region of North Jeolla Province in Korea," Journal of Ethnopharmacology, vol. 137, no. 1, pp. 167-175, 2011.

[29] T. B. Lee, Illustrated Flora of Korea, Hyangmunsa, Seoul, Republic of Korea, 1979.

[30] J. Y. Lee, Coloured Korean Mushroom, vol. 1, Academy Publishing, Seoul, South Korea, 1993.

[31] D. G. Ahn, Illustrated Book of Korean Medicinal Herbs, Kyohak Publishing, Seoul, Republic of Korea, 2002.

[32] Y. N. Lee, Flora of Korea, Kyohak Publishing, Seoul, Republic of Korea, 2002.

[33] J. H. Park, Korean Folk Medicine with Color Pictures, Shinil Books, Seoul, South Korea, 2005.

[34] "National Knowledge and Information System for Biological Species (NKISBS)," 2013, http://www.nature.go.kr/.

[35] R. W. Douglas and U. Johansen, Network Analysis and Ethnographic Problems: Process Models of a Turkish Nomad Clan, Lexington Books, Idaho Falls, Idaho, USA, 2006.

[36] N. A. Christakis and J. H. Fowler, "The spread of obesity in a large social network over 32 years," The New England Journal of Medicine, vol. 357, no. 4, pp. 370-379, 2007.

[37] N. A. Christakis and J. H. Fowler, "Social contagion theory: examining dynamic social networks and human behavior," Statistics in Medicine, vol. 32, no. 4, pp. 556-577, 2013.

[38] N. A. Christakis and J. H. Fowler, "Rejoinder to commentaries on Social contagion theory," Statistics in Medicine, vol. 32, no. 4, pp. 597-599, 2013.

[39] S. P. Borgatti, NetDraw Software for Network Visualization, Analytic Technologies, Lexington, Ky, USA, 2002.

[40] S. P. Borgatti, M. G. Everett, and L. C. Freeman, Ucinet for Windows: Software for Social Network Analysis, Analytic Technologies, Harvard, Mass, USA, 2002.

[41] K. Srithi, H. Balslev, P. Wangpakapattanawong, P. Srisanga, and C. Trisonthi, "Medicinal plant knowledge and its erosion among the Mien (Yao) in northern Thailand," Journal of Ethnopharmacology, vol. 123, no. 2, pp. 335-342, 2009.

[42] Y. H. Kim, Social Inter-Network Analysis, Parkyongsa, Seoul, Republic of Korea, 2013. 


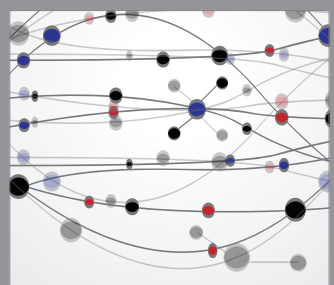

The Scientific World Journal
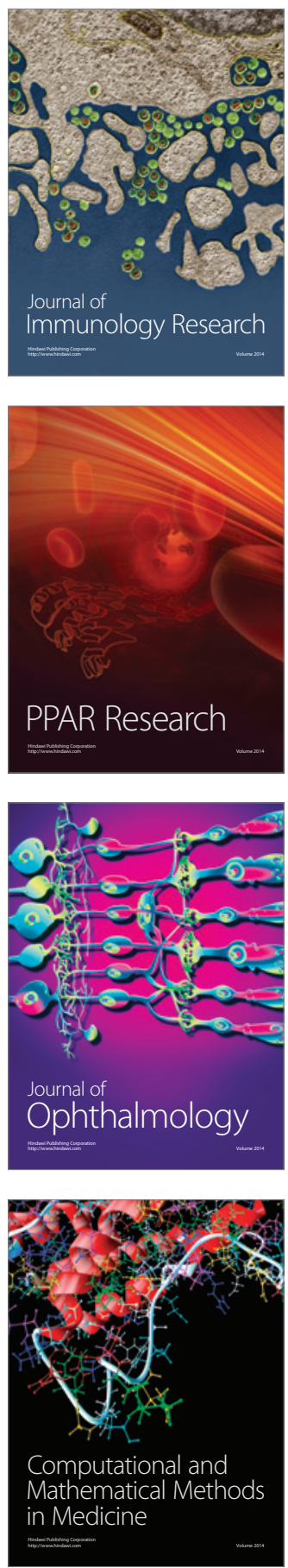

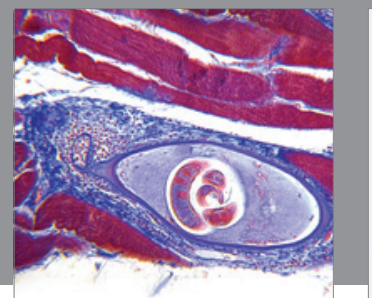

Gastroenterology

Research and Practice
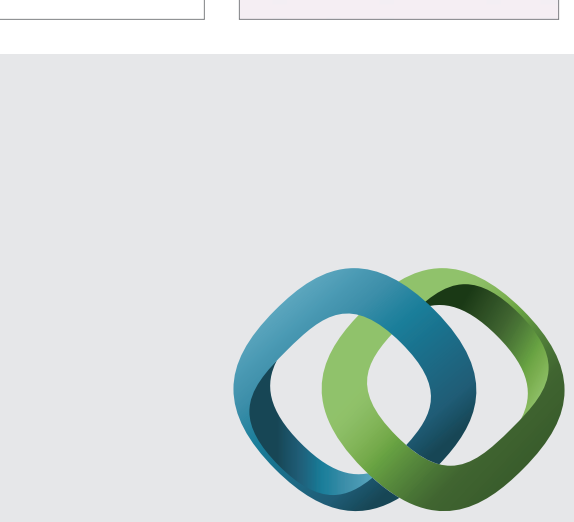

\section{Hindawi}

Submit your manuscripts at

http://www.hindawi.com
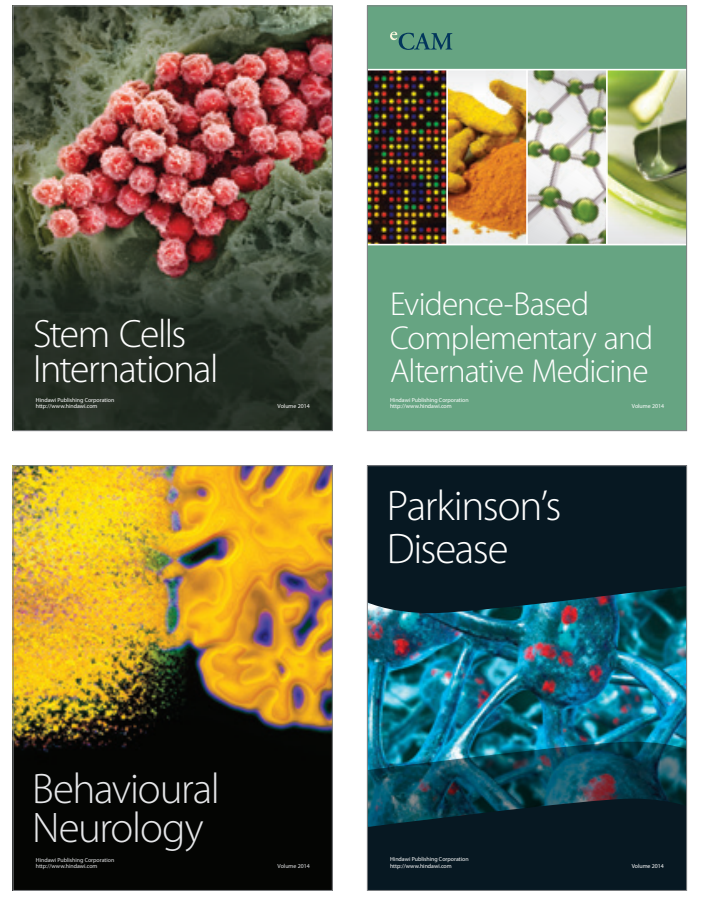
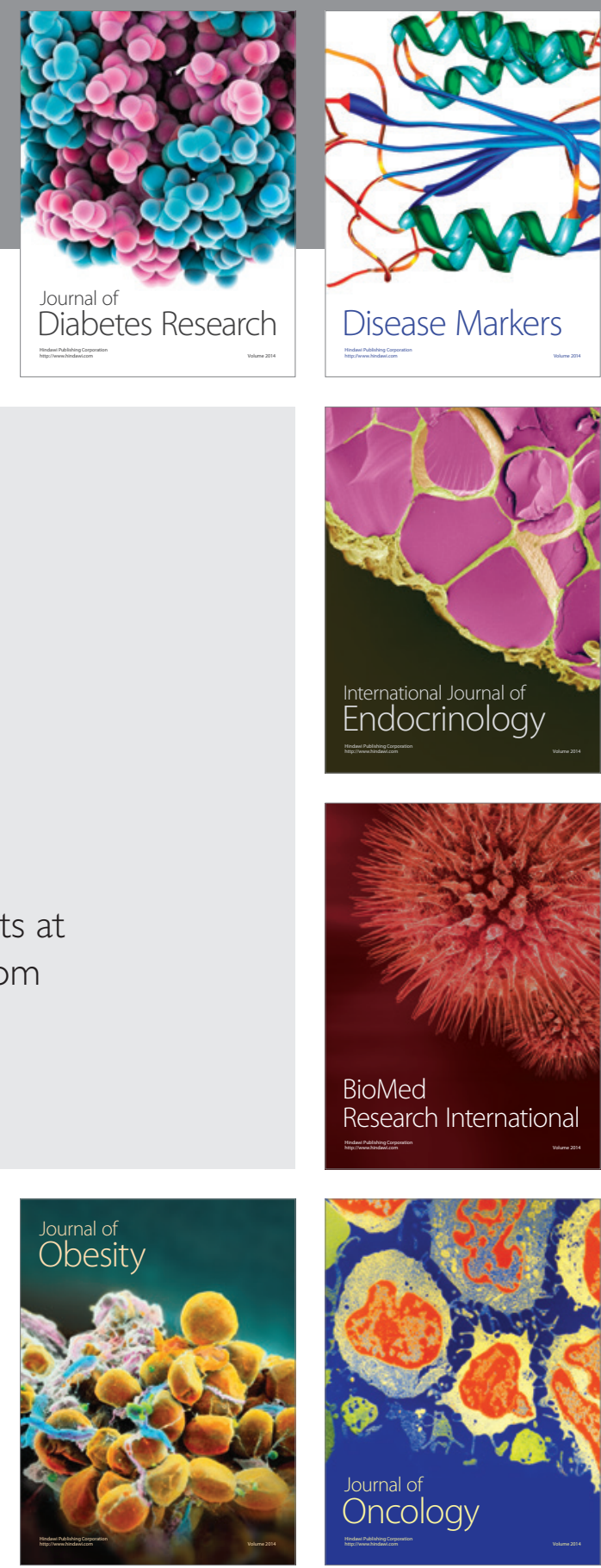

Disease Markers
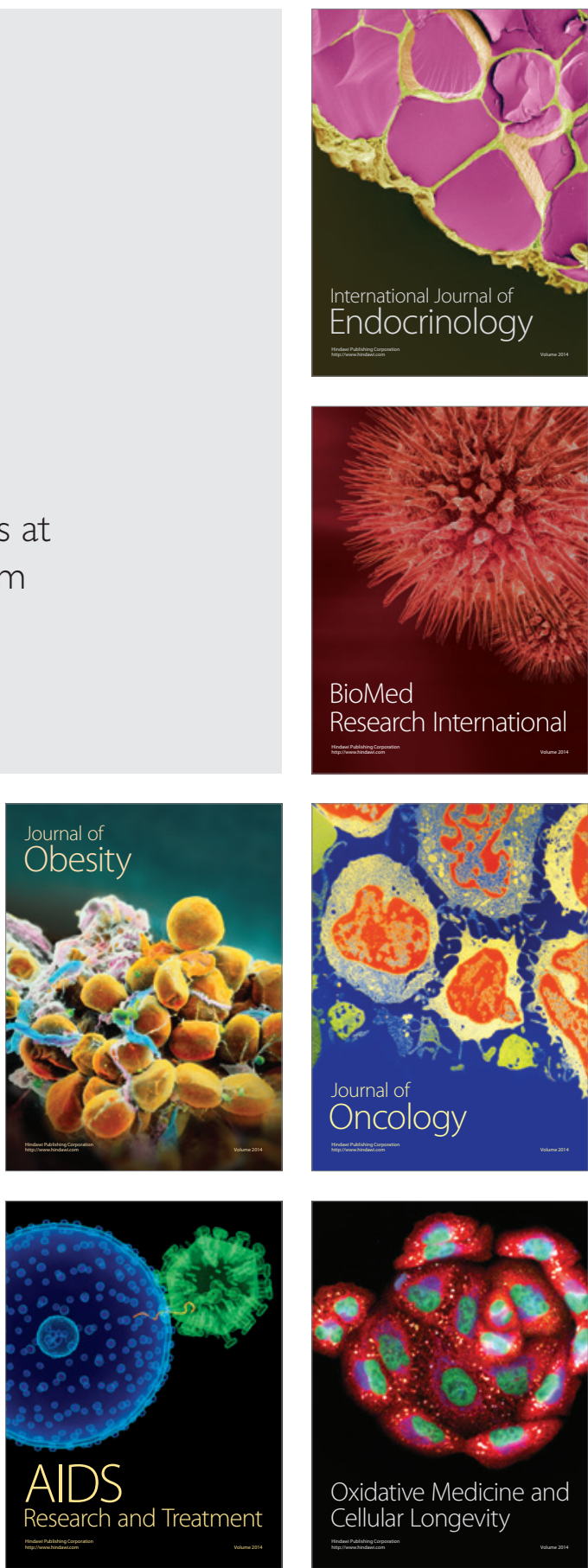